\title{
Three-dimensional inversion analysis of an in situ stress field based on a two-stage optimization algorithm*
}

\author{
She-rong ZHANG ${ }^{1,2}$, An-kui HU ${ }^{1,2}$, Chao WANG ${ }^{\dagger 1,2}$ \\ $\left({ }^{1}\right.$ State Key Laboratory of Hydraulic Engineering Simulation and Safety, Tianjin University, Tianjin 300072, China) \\ $\left({ }^{2}\right.$ School of Civil Engineering, Tianjin University, Tianjin 300072, China) \\ †E-mail: wangchaosg@tju.edu.cn
}

Received Jan. 11, 2016; Revision accepted Feb. 19, 2016; Crosschecked Sept. 12, 2016

\begin{abstract}
Establishing an accurate in situ stress field is important for analyzing the rock-mass stability of the underground cavern at the Huangdeng hydropower station in China. Because of the complexity and importance of the in situ stress field, existing back analysis methods do not provide the necessary accuracy or sufficiently recognize nonlinear relations between the distribution of the in situ stress field and its formative factors. Those factors are related to the geological structures of high compressive tectonic stress regimes, including geological faults and tuff interlayers. The new two-stage optimization algorithm proposed in this paper is a combination of stepwise regression (SR), difference evolution (DE), support vector machine (SVM), and numerical analysis techniques. Stepwise regression is used to find the set of unknown parameters that best match the modeling prediction and determine the range of parameters to be recognized. Difference evolution is used to determine the optimum parameters of the SVM. The SVM is used to create the DE-SVM nonlinear reflection model to obtain the optimal values of the parameters from measured stress data. We compare the new two-stage optimization algorithm to other two popular methods, a multiple linear regression (MLR) analysis method and an artificial neural network (ANN) method, to estimate the in situ stress field for the actual underground cavern at the Huangdeng hydropower station. The two-stage optimization algorithm produces a more realistic estimate of the stress distribution within the investigated area. Thus, this technique may have practical applications in realistic scenarios requiring efficient and accurate estimations of the in situ stress in a rock-mass.
\end{abstract}

Key words: In situ stress, Stepwise regression (SR), Difference evolution (DE), Support vector machine (SVM), Finite element, Huangdeng underground cavern http://dx.doi.org/10.1631/jzus.A1600014

CLC number: TU931

\section{Introduction}

The in situ stress field is widely known to be a fundamental factor for not only the analysis, design calculation, and stability assessment of rock engineering projects, but also the study of rock-mass de-

\footnotetext{
${ }^{\ddagger}$ Corresponding author

* Project supported by the Foundation for Innovative Research Groups of the National Natural Science Foundation of China (No. 51321065), the National Natural Science Foundation of China (No. 51509182), and the Tianjin Youth Research Program of Application Foundation and Advanced Technology (No. 15JCQNJC08000), China (iD) ORCID: She-rong ZHANG, http://orcid.org/0000-0002-7140-1878; Chao WANG, http://orcid.org/0000-0003-1853-2833 (C) Zhejiang University and Springer-Verlag Berlin Heidelberg 2016
}

formation and failure (Guo et al., 1983; Gong et al., 2010). The accuracy of the in situ stress field obtained by numerical simulation directly influences the final results, especially for excavations in high level tectonic stress areas (González de Vallejo and Hijazo, 2008). Therefore, it is essential to know the magnitude and direction of in situ stress for any underground project before construction, requiring extensive measurements and calculations.

The in situ stress field results from a highly complicated process and is affected by many factors, including topography, geological history, the behavioral evolution of rocks, tectonic evolution, the geothermal field, and groundwater. In situ measurement is the most direct approach for determining the 
geo-stress field (Liu et al., 2014). However, such field tests are often costly and time-consuming. Furthermore, due to the complexity brought by the formation of in situ stress and the excessive working impact, the measured results are only a reflection of the local stress field. Thus, based on the measurement results and geological structure conditions, it is crucial to derive a reasonable stress field with wide applicability using a convenient and efficient back analysis approach coupled with an advanced numerical simulation method (Mckinnon, 2001; Saati and Mortazavi, 2011).

In numerical simulations, the in situ stress fields are generally acquired by a number of methods using limited measurement and topography data used for design and construction at various engineering sites (Zhang et al., 2006; Guo et al., 2008; Qin et al., 2008). These methods include multiple linear regression (MLR) analysis, artificial neural network (ANN) methods (Kartam et al., 1997; Xu, 2000; Li et al., 2012; Samui et al., 2015), and genetic algorithm optimization approaches, which have been adopted extensively within stress boundary conditions and displacement boundary conditions in particular. However these methods have unique limitations, specifically in terms of shortcomings in the speed and accuracy of the inverse analysis of the in situ stress field.

Under uniform lithology and relatively simple geological conditions, the MLR analysis method for in situ stress estimation has been applied in many construction sites to assess the regional in situ stress because of its speed and convenience. However, the interaction of the main factors affecting the in situ stress field is ignored by the substantial assumptions about linearity and continuity. Moreover, the relationship between the in situ stress field and the main factors is too complicated to express by a subharmonic multivariate function. Therefore, the MLR analysis method usually lacks conformity with the practical situation and eventually leads to significant inaccuracy. As a typical surrogate direct inversion, the ANN approach attempts to use machine learning to map the nonlinear inverse relationship between the stress measurements and the boundary conditions (Grossberg, 1988; Kartam et al., 1997) but often has difficulty traversing the typically non-convex optimization search space because of its inherent limitations, including non-uniqueness, non-existence, and instability. Moreover, it relies mostly on a specifically designed algorithm and a high-accuracy digital computer to ensure satisfactory results, often at the expense of convergence speed. Alternatively, the genetic algorithm is a well-known optimizationbased approach used to solve the inverse problem to determine the distribution of the in situ stress field. However, this method is prone to problems of premature convergence. In other words, it easily converges to a local optimal solution and requires a large number of forward analyses to estimate a solution. This means that it is typically computationally expensive with unnecessary time costs. Moreover, its solution accuracy depends strongly on the selection of the initial population. Given the limitations of these methods, one logical approach is to combine stepwise regression (SR), difference evolution (DE), support vector machine (SVM), and numerical analysis techniques to solve the inverse problem and estimate a stress field that more effectively addresses the need for both accuracy and computational efficiency (Grossberg, 1988; Kartam et al., 1997).

This paper presents the details of a particularly promising approach incorporating linear regression, SVM, and DE, and applies this approach to the problem of inversely obtaining the in situ stress field in underground projects. In the following section, considering the effect of the unloading of land surface denudation, we determine a series of parameters to be estimated related to the formation of the rockmass in situ stress field. First, we provide an outline and the technological process of a two-stage optimization algorithm and its incorporation into an inverse solution method, namely the SR-DE-SVM algorithm, for estimating the in situ stress in a rock-mass. Then, we use this method to estimate a set of unknown parameters at the underground caverns at the Huangdeng hydropower station, using a numerical analysis to assess the efficacy of the SR-DE-SVM approach. Finally, we present validation tests.

\section{Land surface denudation theory for the magnitude of in situ stress}

\subsection{Denudation effect of unloading}

In the long term, the geological history and behavioral evolution of rocks may significantly 
influence the state of in situ stress fields. Some research has shown that the distribution of the rockmass in an in situ stress field is strongly influenced by the land surface denudation effects of unloading resulting from an intense geological process when the geological environment is complicated (Hijazo and González de Vallejo, 2012). Consequently, the unloading geological behaviors stemming from land surface denudation must be considered to obtain a reasonable assessment of the in situ stress. The in situ stress field in high-mountain gorge areas is the inevitable result of various unloading geological behaviors, including land surface erosion and valley denudation, which disequilibrate the state of rockmass stress before the formation of a valley, leading to a new balanced state through the simultaneous adjustment of its stress and strain.

To express the effect of land surface denudation, several reasonable and necessary assumptions should be made, namely, that the land was sufficiently even in ancient times and, based on geological mechanics analysis, that the in situ stress comes mainly from gravity and the geological tectonic stress field (Guo, et al., 2008) applied in ancient times. The formation of a rock-mass in situ stress field involves many related factors, such as topography, lithology, geological and structural anisotropies, sedimentary loads, tectonic evolution, thermal conditions, and groundwater. However, the thermal stress is equal to only $1 / 9$ of the gravity stress. Thus, the thermal stress effect on the rock-mass in situ stress field is negligible for common underground projects. Conversely, groundwater has an intricate mechanism of influence on the in situ stress. Specifically, an increase in pore pressure can reduce the shear strength of the rock in the potential structural plane. Moreover, seepage pressures usually change the in situ stress field in underground projects. The thermal conditions and groundwater are usually ignored in analyses because of their comparatively small influence and difficult quantification. The last assumption is that the estimated in situ stress field is created by land denudation and erosion in the context of an ancient in situ stress field.

\subsection{Land surface denudation simulation}

Six types of displacement boundary conditions were considered in the simulation analysis to repre- sent the different effects of land surface denudation and river erosion (Fig. 1) (Jiang et al., 2008), reflecting the distribution of the in situ stress field under different effects of unloading in underground projects.

\section{Two-stage optimization algorithm for es- timating inverse in situ stress}

The two-stage optimization algorithm is a nonlinear global optimization method that combines SR and SVM with DE. It has been shown to be capable of effectively solving global optimization problems with relatively low use of computational resources (Jiang et al., 2013). SR can ascertain the set of unknown parameters that best matches the modeling prediction and determine the range of parameters to be recognized. DE is applied to determine the optimum parameters of the SVM. The SVM is used to create the DE-SVM nonlinear reflection model that maintains the global search capabilities over the whole search space to efficiently determine an optimal solution interval.

\subsection{Methodology of the stepwise regression}

As a prominent multivariate function, the SR method uses its specific and available efficiency to determine the importance of numerous influencing parameters to obtain the best combination of variables to establish functional relations, especially in a complex system. The selection of the initial parameters strongly influences the evolution velocity of the SVM. Improper parameter selection may lead to generation stagnancy or premature phenomena, failing to satisfy the analysis request. The proposed method introduces SR into the in situ stress field inversion analysis to define the causes of the formation of the in situ stress more clearly and to provide an important basis for underground cavern design and stability analysis.

Simulation of a tectonic stress field is usually conducted by applying normal or tangential displacement or stress boundary conditions, whose consistency relative to each other is ignored. However, the entry of one factor will lead to degradation of the others. Thus, after calculation and comparison, SR is used to exclude those factors that do not play a 

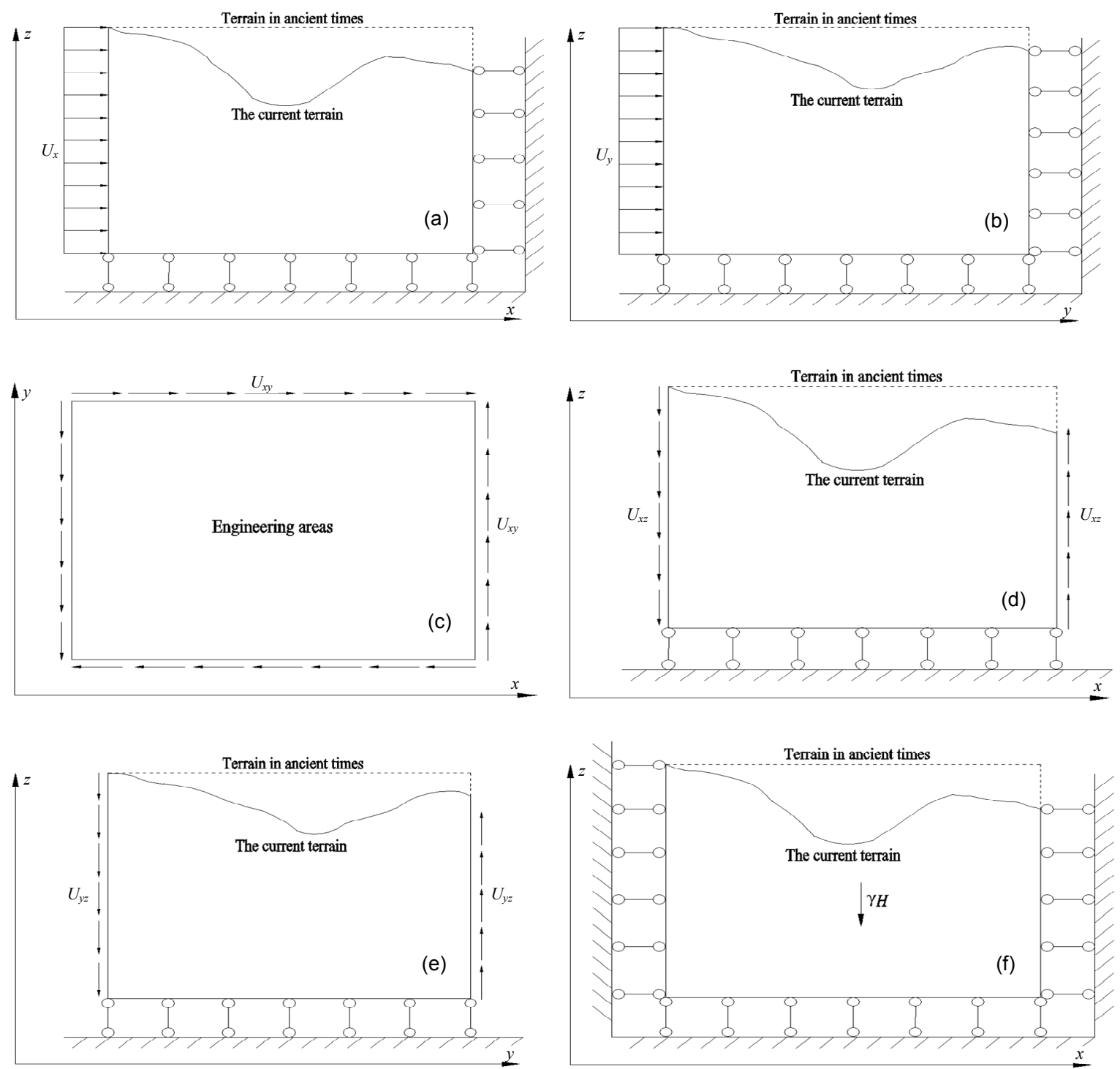

Fig. 1 Schematic diagram of the displacement boundary conditions

(a) Tectonic movement boundary in the $x$ direction, $U_{x}$; (b) Tectonic movement boundary in the $y$ direction, $U_{y}$; (c) Shear tectonic movement boundary in the $x y$ plane, $U_{x y}$; (d) Shear tectonic movement boundary in the $x z$ plane, $U_{x z}$; (e) Shear tectonic movement boundary in the $y z$ plane, $U_{y z}$; (f) Boundary condition under a gravity function. $\gamma$ is the unit weight of the rock mass; $H$ is the depth of its location

dominant role in the region of interest. The SR filters and inspects each tectonic stress factor that may be influential and that is consistent with the existing structural features to obtain an optimized solution matching the engineering geological investigation data.

The in situ stress value can be represented by the following equation:

$$
\sigma_{j k}^{0}=C_{0}+\sum_{i=1}^{n} C_{i} \sigma_{j k}^{i}+\varepsilon
$$

where $\sigma_{j k}^{0}$ is the calculated initial geo-stress value of stress component $j$ on point $k, C_{0}$ is a constant coefficient, $C_{i}$ represents a stress component caused by each movement pattern, including gravity movement and sub-tectonic movement patterns, $\sigma_{j k}{ }^{i}$ is the calculated geo-stress value of stress component $j$ under gravity and sub-tectonic movement on point $k$, and $\varepsilon$ is the model error.

First, we assume that $H_{0}: C_{0}=C_{1}=C_{2}=\ldots=C_{n-1}$ $=C_{n}=0$ and check $H_{0}$ using test data as a statistical sample. If $H_{0}$ is rejected, the linear regression is 
significant, which indicates that a linear relationship exists between the independent and dependent variables. If not, the regression is not significant, which indicates that the regression model does not work.

The core concept of SR is to introduce impact factors one by one under the condition that the factor has an obvious sum of squares of partial regression. The previous factors are then inspected individually after adding new factors to exclude those without obvious relationships, ensuring that the optimal subset of variables can be obtained in several steps. The method is simple and fast because there is no need to determine the partial correlation coefficients.

The least square SR method is adopted to conduct a statistical analysis of the effect of different parameters to be estimated on target parameters. The $F$-test is applied to check whether the regression is significant, where the statistical magnitude of $F$ has the computational formula shown in Eq. (2). Furthermore, the ratio of the regression sum of squares and the residual sum of squares obeys the distribution $F$, whose degree of freedom is $m$ and $n-m-1$ :

$$
F=\frac{U / m}{Q /(n-m-1)} \sim F(m, n-m-1),
$$

where $U=\sum_{k=1}^{n}\left(\hat{y}_{k}-\bar{y}\right)^{2}$ is the regression sum of squares, which is the sum of squares of the difference between the regression value $\hat{y}_{k}$ and the average value $\bar{y}, m$ is the number of variables, $n$ is the sample number, and $Q=\sum_{k=1}^{n}\left(y_{k}-\hat{y}_{k}\right)^{2}$ is the residual sum of squares, namely, the sum of squares of the difference between the measured value $y_{k}$ and the regression value $\hat{y}_{k}$.

The $F$ statistic can be used to quantify the overall effect of the regression; the larger the $F$ value is, the better the regression equation is. For the given confidence level $\lambda$ ( $\lambda=95 \%$ is commonly adopted), the $F$ statistic should satisfy

$$
P\left(F \leq F_{\lambda}(m, n-m-1)\right) \leq 1-\lambda .
$$

If Eq. (3) does not hold, the assumption fails.

The procedure for SR is as follows:

1. Independent variables are adopted to conduct the linear regression statistics for dependent varia- bles and to check the $F$ value.

2. The effect on the dependent variables of the independent variables that are sequentially added to the regression equation is observed. The effect can be determined by both the coefficient of partial correlation between the two variables and the $F$ value regressed by them.

3. If the independent variables introduced earlier become less significant due to the introduction of latter variables, the earlier variables are eliminated.

4. Steps 2 and 3 are repeated until no additional insignificant variables are present in the equation and no additional significant variables are added into the equation. Each time that steps 2 and 3 are repeated, the $F$ value is checked to confirm the significance of the effect of the independent variables on the dependent variables.

\subsection{Nonlinear model based on DE-SVM}

The SVM is a preeminent machine learning tool that minimizes an upper bound on its expected error. It attempts to convert low-dimensional nonlinear problems into high-dimensional linear problems and then replace inner product computation with a kernel function. More specifically, given data points $x_{1}$, $x_{2}, \ldots, x_{n}$ and class labels $y_{1}, y_{2}, \ldots, y_{n}$, the SVM has the form:

$$
y_{i}=f(x)=(\boldsymbol{w} \cdot x)+b^{*}=\sum_{i=1}^{n}\left(\boldsymbol{\alpha}_{i}^{*}-\boldsymbol{\alpha}_{i}\right)\left(x_{i} \cdot x\right)+b^{*} .
$$

Let $\boldsymbol{w}$ be the weighted vector and $x_{i} \in \mathbb{R}^{d}$, $y_{i} \in \mathbb{R}$. Furthermore, let $\boldsymbol{\alpha}_{i}$ and $\boldsymbol{\alpha}_{i}^{*}$ be the support vectors, on which all of the classifications performed by the SVM solely depend. Finally, $b^{*}$ represents the classification threshold. Thus, an identical SVM would result from a training set that omits all of the remaining examples. The data representation in this feature space need not be explicitly calculated if there is an appropriate Mercer kernel operator for which

$$
k\left(x, x_{i}\right)=\exp \left(-\frac{\left|x-x_{i}\right|^{2}}{2 \sigma^{2}}\right) .
$$

A radial basis function is adopted as the typical Mercer kernel operator due to its excellent performance, meaning that the data that are not linearly 
separable in the original space may become separable in this feature space. For data sets that are nonseparable, slack variables $\xi_{i}$ and $\xi_{i}^{*}$ are introduced to relax the constraint as

$$
\min \left[\frac{1}{2}\|\boldsymbol{w}\|^{2}+c \sum_{i=1}^{n}\left(\xi_{i}+\xi_{i}^{*}\right)\right]
$$

subject to $\xi_{i} \geq 0, \xi_{i}^{*} \geq 0$, and $c \geq 0$, representing a constant called the penalty parameter. An optimal model can usually be achieved by seeking the best values of $c$ and $k$, which play an important role in its prediction accuracy. However, the SVM never provides systematic theoretical approaches for the two parameters.

A DE algorithm is designed to fulfill user requirements, as its control variables are robust and easy to select and it has good convergence to the global minimum in consecutive independent trials (Xing et al., 2015). In this study, we used the advantages of the $\mathrm{DE}$ algorithm to explore the best parameters of $c$ and $k$ in SVM modeling due to its simple but efficient global optimization performance (Cheng et al., 2013). The improved DE-SVM algorithm includes the following steps:

1. Initializing of the DE-SVM parameters, which entails randomly generating $N_{\mathrm{p}}$ bivectors about $c$ and $k$ in SVM modeling that should be satisfied to restrain the upper and lower bound independent variables. Because the $\mathrm{DE}$ algorithm is designed to be a stochastic real parameter optimization algorithm, its formula is as follows:

$$
\boldsymbol{x}_{i j}=\boldsymbol{x}_{i j}^{\mathrm{L}}+\operatorname{rand}\left(\boldsymbol{x}_{i j}^{\mathrm{U}}-\boldsymbol{x}_{i j}^{\mathrm{L}}\right),
$$

subject to $i=1,2, \ldots, N_{\mathrm{p}}$, where $N_{\mathrm{p}}$ represents the population size, $j=1,2$ is the dimension of the vectors, $\boldsymbol{x}_{i j}^{\mathrm{U}}$ and $\boldsymbol{x}_{i j}^{\mathrm{L}}$ are the upper and lower bound independent variables, respectively, and the function rand is random and rand $\in[0,1]$.

2. In mutation, the difference between two independent vectors is minimized and then merged with a third independent vector in its population, forming a new variation vector. For the target vector $\boldsymbol{x}_{i j}$, the mutant vector is obtained according to

$$
\boldsymbol{v}_{i j}(G+1)=\boldsymbol{x}_{r_{1} j}(G)+F\left(\boldsymbol{x}_{r_{2} j}(G)-\boldsymbol{x}_{r_{3} j}(G)\right),
$$

where $r_{1}, r_{2}, r_{3} \in[1, n]$, which are random indexes. $r_{1}$, $r_{2}$, and $r_{3}$ are chosen to be different from the running index $i$; thus, $n \geq 4$ to allow for this condition. $F \in[0,2]$, where $F$ determines the amplification of the differential variation $\boldsymbol{x}_{r_{2} j}(G)-\boldsymbol{x}_{r_{3} j}(G)$, and $G$ stands for generation.

3. Crossover increases the diversity of the perturbed parameter vectors. Each vector in the current population is combined with a mutant to produce a trial population in this step (Jiang et al., 2013). The trial vectors are expressed as

$$
\boldsymbol{u}_{j i, G+1}= \begin{cases}\boldsymbol{v}_{j i, G+1}, & r_{j} \leq \mathrm{CR} \text { or } j=r n_{i}, \\ \boldsymbol{x}_{j i, G}, & r_{j}>\mathrm{CR} \text { and } j \neq r n_{i},\end{cases}
$$

where $j=1,2, \ldots, n ; r_{j}$ is a random number between 0 and $1 ; \mathrm{CR} \in[0,1]$, called a crossover constant, is determined by the user, and $r n_{i} \in[1, n]$, which ensures that $\boldsymbol{u}_{j i, G+1}$ obtains at least one vector parameter from $\boldsymbol{v}_{j i, G+1}$.

4. Selection is then performed to determine whether the target or trial vector survives to become a member of the next generation. If the trial vector $\boldsymbol{u}_{j i, G+1}$ yields a smaller cost function value than the target vector $\boldsymbol{x}_{j i, G}$, then the target vector $\boldsymbol{x}_{j i, G}$ can replace the trial vector $\boldsymbol{u}_{j i, G+1}$. That is, the target vector $\boldsymbol{x}_{j i, G}$ is not itself replaced.

5. Loop iteration is conducted, repeating steps 2 to 4 , until the end condition for the optimization process is reached. This end condition is set as a maximum generation $G_{\max }$ or maximum number of function evaluations, which can be specified by the user to avoid over-fitting. Therefore, the optimal parameters will be obtained when the process reaches the convergence stage, indicating that the optimum parameters are provided for the SVM, allowing it to create an excellent model.

\subsection{SR-DE-SVM algorithm}

To describe the SR-DE-SVM algorithm as specifically implemented here for the in situ stress inverse problem, in which the boundary conditions are set to be unknown parameters and the objective function minimizes the error between the measured stress and the calculated stress at several measurement points, a nonlinear model based on the SVM is 
defined as follows:

$$
\begin{gathered}
Y=\operatorname{SVM}(X), \\
X=\left(x_{1}, x_{2}, \cdots, x_{n}\right), \\
Y=\left(y_{1}, y_{2}, \cdots, y_{m}\right),
\end{gathered}
$$

where $Y$ is the measured stress of the engineering site, $X$ is the estimated boundary condition, and $m$ and $n$ are the numbers of input variables and output variables, respectively.

Thus, this constrained optimization problem can be expressed as

$$
\begin{gathered}
\min E\left(x_{1}, x_{2}, \cdots, x_{n}\right)=\frac{1}{m} \sum_{i=1}^{m}\left(y_{i}-\mathrm{SVM}_{i}\right)^{2}, \\
x_{i}^{\mathrm{a}} \leq x_{i} \leq x_{i}^{\mathrm{b}}, \quad i=1,2, \cdots, n,
\end{gathered}
$$

where $\mathrm{SVM}_{i}$ represents the stress predicted by the SVM algorithm, and $x_{i}^{\mathrm{a}}$ and $x_{i}^{\mathrm{b}}$ are the upper and lower bounds of $x_{i}$, respectively.

Therefore, the objective of the algorithm is to minimize the function $\min E(X)$. Fig. 2 shows an overview of the SR-DE-SVM algorithm. The recognition process of the boundary conditions is summarized briefly in the following steps:

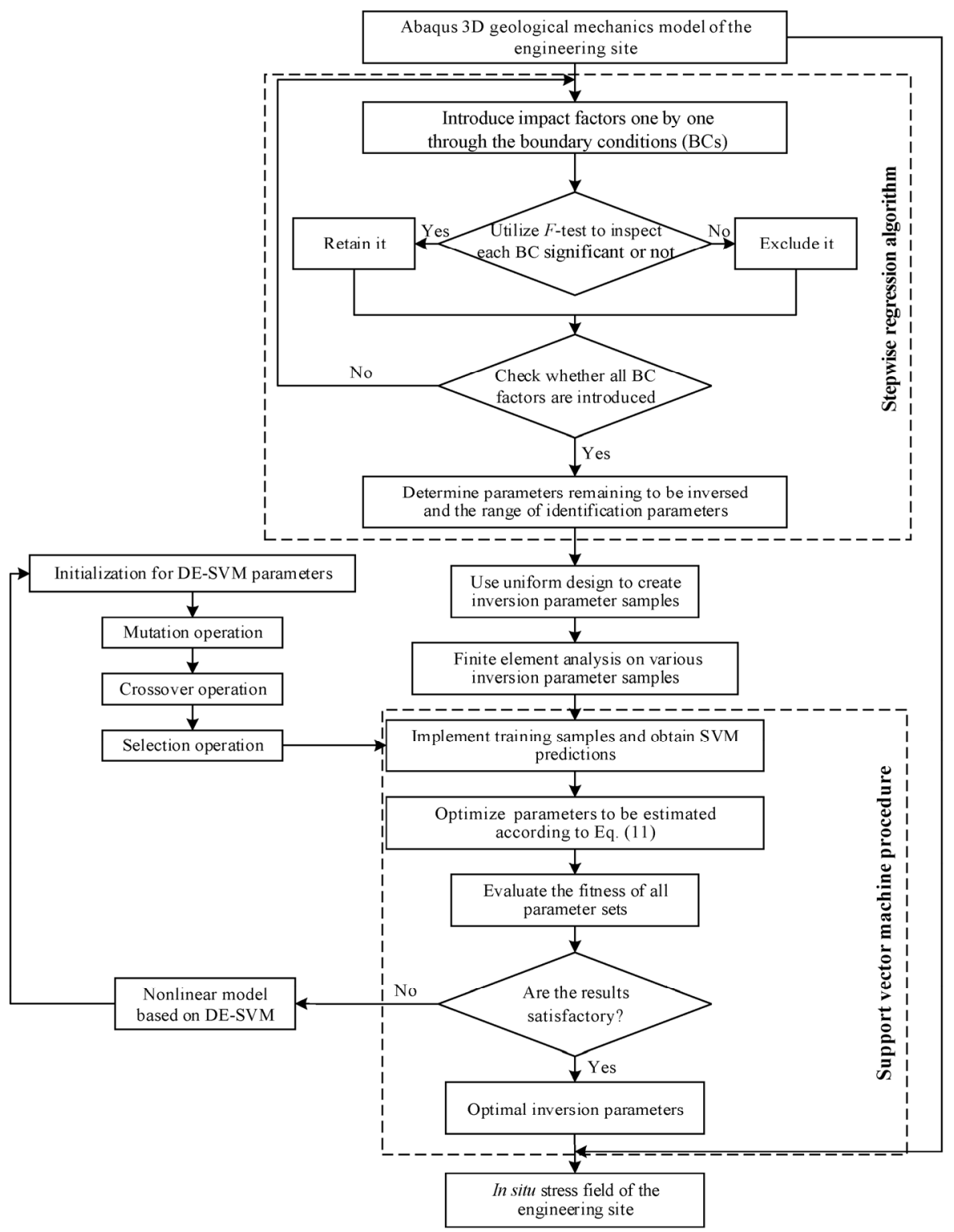

Fig. 2 Flow chart of the SR-DE-SVM algorithm 
Step 1: The stepwise regression algorithm attempts to determine the range of parameters to be recognized and the genetic parameters (Feng et al., 2000). This avoids the blindness of the sample generation based on Eq. (1).

Step 2: Inversion parameter samples are created based on uniform design.

Step 3: The 3D geological mechanics model of the engineering site is established completely. After the numerical calculation of each combination of boundary conditions, the corresponding calculated stress is obtained at several measurement points. Each combination of boundary conditions with its corresponding calculated stress comprises a socalled learning sample.

Step 4: Based on the object function, Eqs. (5) and (6), the DE approach is typically used to discover optimal parameters for SVM modeling.

Step 5: A nonlinear model based on DE-SVM is created to describe the relationship between the boundary conditions to be estimated and the actual measured stress.

Step 6: Based on the object function, Eq. (11), the SR-DE-SVM algorithm is used to refine the search using the input-output information generated by the random search. Using the optimal inversion parameters, the distribution of the in situ stress field can then be obtained for the engineering site by computerized simulation.

\section{Application to the Huangdeng hydropower station}

\subsection{On-site in situ stress measurement in under- ground cavern zones}

\subsubsection{Brief description of geological features}

The Huangdeng hydropower station is located in Lanping County, Nujiang, Yunnan Province, China. It is part of the fifth stage of a reservoir with seven stations planned along the Lantsang River, and connects the Toba hydropower station upstream to the Dahuaqiao station downstream. Its power generation system is located on the left bank of the station hydropower complex, consisting of the power house, auxiliary plant, transformer chamber, tailrace surge chamber, overhaul gate chamber, pressure tunnels, tailrace branch tunnels, and tailrace tunnels, with large-scale caverns arranged in a crisscross pattern.

Tectonically, the Huangdeng hydropower station is situated on the east side of overturned synclines and on the west side of overturned anticlines in Kedengjian. The rock stratum runs perpendicular to the river at attitudes of $\mathrm{N} 10^{\circ}-20^{\circ} \mathrm{E}, \mathrm{NW} \angle 75^{\circ}-90^{\circ}$. Generally, the rock stratum in the power house, auxiliary plant room, transformer chamber, maintenance chamber of the unit tail water, and the surge tank is composed of metamorphic volcanic breccias, a metamorphic volcanic granule conglomerate mixed with metamorphic tuff, whose rock quality designations (RQDs) are $75 \%-90 \%$ and $60 \%-75 \%$, respectively, and in the corresponding $Q$-system for rock mass classification $Q=10-40$ and $Q=1-10$, respectively, in moderately weathered, slightly weathered, and fresh states. Fig. 3 shows the main faults crossed over by the Huangdeng underground cavern group at an elevation of $1480 \mathrm{~m}$, in which five main geological faults, $F_{9}, F_{230-1}, F_{14}, f_{20}$, and $f_{230-1}$, and tuff interlayers $t_{p 230-1}$ are a key focus of attention. The rock is relatively intact and slightly permeable, meaning that although the geological conditions are relatively complex in this region, the lithology is rather uniform.

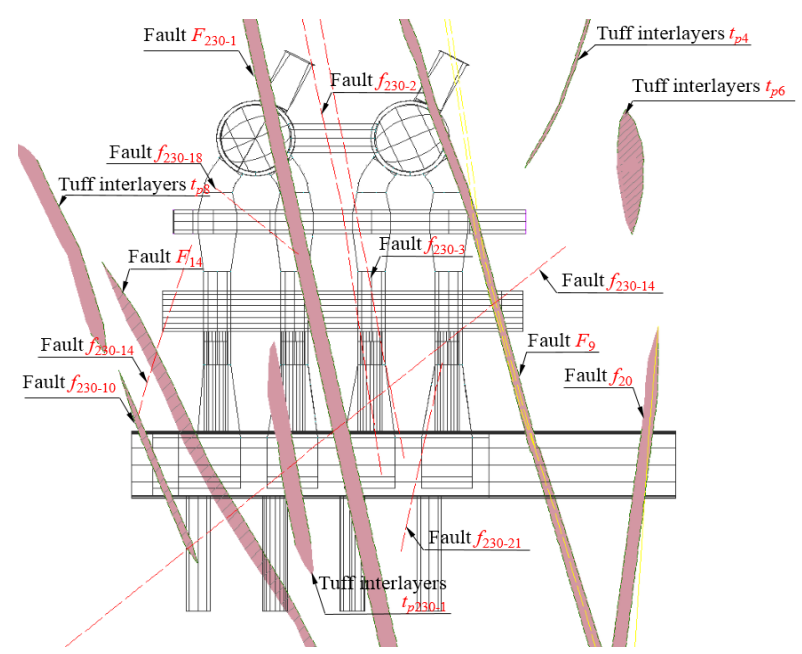

Fig. 3 Main faults crossed over by the Huangdeng underground cavern group at an elevation of $1480 \mathrm{~m}$

Furthermore, the Huangdeng engineering area lies in the secondary tectonic units from the central part of the geosynclinal fold system in Tanggula, 
Lanping, and Simao, which is located in the southwestern part of the Sichuan-Yunnan rhombic block, and the northern parts of the Indochina and YunnanBruma blocks. The crustal blocks show the characteristics of heterogeneous and asymmetrical uplifting in the whole engineering area. This means that, in general, the terrain is higher in the north and lower in the south. Note that it is part of active structure zones. The direction of fault structures is NNW or trending towards a NS direction, and the faults can be divided into two major types, the Early and Middle Pleistocene and the Quaternary faults. However, no Late Pleistocene faults are found in the underground cavern group zone, and there are no fault structures in the region that might induce a strong destructive earthquake. Moreover, the Huangdeng project is located in the interior of active blocks, and no large or deep active faults cross over the region. Furthermore, it does not lie at the boundary of geotectonic and neo-tectonic areas, and no moderate or intense earthquakes have been recorded. Therefore, on the whole, the Huangdeng engineering region belongs to an area with good structural stability.

\subsubsection{Test results and discussion}

To study the in situ stress distribution of the engineering area, in situ stress measurements were made in the underground power house with highpressure branch pipes using the aperture deforming method with three boreholes. This approach can provide information for the design of the arrangement of the engineering structures, the selection of the excavation methods, and the stability analysis and supporting design of every building. For the disposed in situ stress, the aperture distortion needs to be measured, and the 3D in situ stress state of the measuring points is obtained according to the relationship between the pitch deformation and the intrinsic in situ stress. In the feasibility phase, this project sets four groups of testing points on the left bank of the PD230 exploration audit of the power house and its inferior branch, which are all located at an elevation of $1527.3 \mathrm{~m}$. A sketch map of the in situ stress measuring points is shown in Fig. 4. Using the method of aperture deformation with three boreholes, four measured stresses could be obtained: $\sigma_{230-1}, \sigma_{230-2}$, $\sigma_{230-3}$, and $\sigma_{230-4}$. The results are shown in Table 1 .

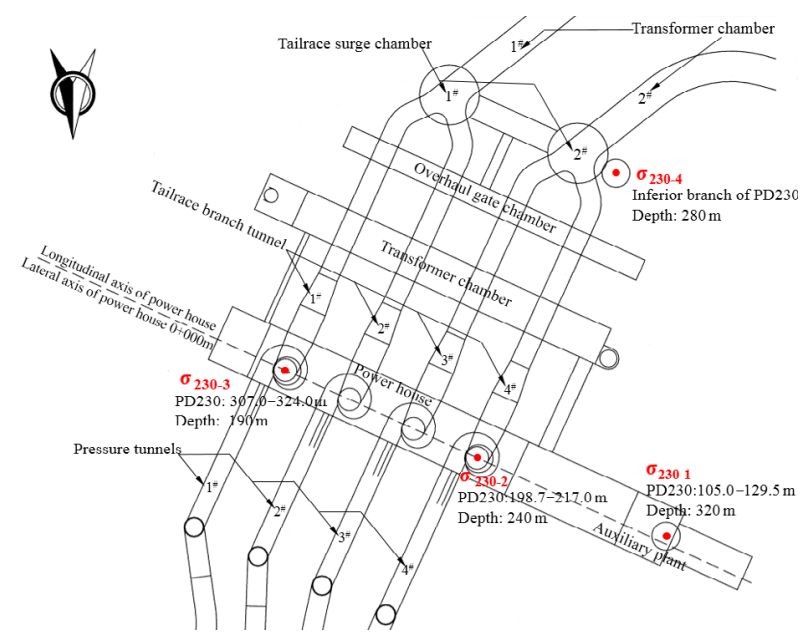

Fig. 4 Layout of the in situ stress measuring points in the underground cavern zones

Both Fig. 4 and Table 1 show that, although the maximum, middle, and minimum principal stresses present significantly dispersed features, they still show a certain regularity. As observed from the maximum measured in situ stress, the $\sigma_{1}$ values for all measured locations are actually in the pressure stress state, with magnitudes between 7.0 $\mathrm{MPa}$ and 15.0 MPa. Furthermore, $\sigma_{1}$ increases as the measuring point depth increases. The values of $\sigma_{2}$ for all measured locations ranged from $2.5 \mathrm{MPa}$ to $7.5 \mathrm{MPa}$, and those of $\sigma_{3}$ ranged from 1.5 MPa to 5.0 MPa. Moreover, the measured maximum principal stress $\sigma_{1}$ was consistent in its direction, which was southnorth or east-west, with a dip angle of $S 15^{\circ}-40^{\circ} \mathrm{E}$ with a positive gradient slope. Its dip angle was slightly smaller than its slope angle, which decreased as the point depth increased.

Generally, the angle $\phi$ between the direction of the measured maximum principal stress $\sigma_{1}$ and the longitudinal axis of the power house should be kept within $15^{\circ}-30^{\circ}$, according to statistical data from several in-built underground cavern projects in China (Table 2). As Table 1 shows, the direction of the measured maximum principal stress $\sigma_{1}$ is $\mathrm{S} 39.7^{\circ} \mathrm{E}$. Therefore, the direction of the longitudinal axis of the power house is determined as NW294.5 . Considering the influence of the geological conditions of the engineering area and the overall coordination of the project, this means that the angle $\phi$ is equal to $25.8^{\circ}$. We conclude that the angles between the direction of the measured maximum principal stress $\sigma_{1}$ 
Table 1 Principal stress results from in situ stress measurements in the underground cavern zones

\begin{tabular}{|c|c|c|c|c|c|c|c|c|c|c|}
\hline \multirow{2}{*}{$\begin{array}{l}\text { Test } \\
\text { point }\end{array}$} & \multirow[b]{2}{*}{ Location } & \multicolumn{3}{|c|}{$\sigma_{1}$} & \multicolumn{3}{|c|}{$\sigma_{2}$} & \multicolumn{3}{|c|}{$\sigma_{3}$} \\
\hline & & $\begin{array}{l}\text { Stress } \\
(\mathrm{MPa})\end{array}$ & $\begin{array}{l}\text { Orienta- } \\
\text { tion }\end{array}$ & $\begin{array}{c}\text { Dip } \\
\text { angle }\left(^{\circ}\right)\end{array}$ & $\begin{array}{l}\text { Stress } \\
(\mathrm{MPa})\end{array}$ & $\begin{array}{l}\text { Orienta- } \\
\text { tion }\end{array}$ & $\begin{array}{c}\text { Dip } \\
\text { angle }\left({ }^{\circ}\right)\end{array}$ & $\begin{array}{l}\text { Stress } \\
(\mathrm{MPa})\end{array}$ & $\begin{array}{l}\text { Orienta- } \\
\text { tion }\end{array}$ & $\begin{array}{c}\text { Dip } \\
\text { angle }\left({ }^{\circ}\right)\end{array}$ \\
\hline$\sigma_{230-1}$ & $\begin{array}{c}\text { PD230: } \\
\text { 105.0-129.5 m; } \\
\text { depth: } 320 \mathrm{~m}\end{array}$ & 6.97 & $\mathrm{~S} 36.4^{\circ} \mathrm{E}$ & 39.7 & 2.49 & $\mathrm{~N} 35^{\circ} \mathrm{E}$ & 21.0 & 1.77 & $\mathrm{~S} 76^{\circ} \mathrm{E}$ & -42.9 \\
\hline$\sigma_{230-2}$ & $\begin{array}{c}\text { PD230: } \\
\text { 198.7-217.0 m; } \\
\text { depth: } 240 \mathrm{~m}\end{array}$ & 11.88 & $\mathrm{~S} 12.6^{\circ} \mathrm{E}$ & 34.3 & 6.17 & $\mathrm{~N} 58.2^{\circ} \mathrm{E}$ & 25.7 & 3.28 & $\mathrm{~S} 60.2^{\circ} \mathrm{E}$ & -44.7 \\
\hline$\sigma_{230-3}$ & $\begin{array}{c}\text { PD230: } \\
\text { 307.0-324.0 m; } \\
\text { depth: } 190 \mathrm{~m}\end{array}$ & 14.63 & $\mathrm{~S} 39.7^{\circ} \mathrm{E}$ & 18.2 & 5.02 & $\mathrm{~N} 86.3^{\circ} \mathrm{E}$ & -60.7 & 1.82 & $\mathrm{~N} 42.6^{\circ} \mathrm{E}$ & 22.1 \\
\hline$\sigma_{230-4}$ & $\begin{array}{l}\text { Inferior branch } \\
\text { of PD230; } \\
\text { depth: } 280 \mathrm{~m}\end{array}$ & 13.25 & $\mathrm{~S} 40.5^{\circ} \mathrm{E}$ & 22.7 & 7.24 & $\mathrm{~S} 81.5^{\circ} \mathrm{E}$ & -61.0 & 4.81 & $\mathrm{~N} 42.1^{\circ} \mathrm{E}$ & 17.1 \\
\hline
\end{tabular}

Table 2 Statistical data from several in-built underground cavern projects in China

\begin{tabular}{|c|c|c|c|c|}
\hline \multirow{2}{*}{ Engineering project } & \multicolumn{2}{|c|}{$\sigma_{1}$} & \multirow{2}{*}{$\begin{array}{l}\text { Orientation of longitudinal } \\
\text { axis of power house }\end{array}$} & \multirow{2}{*}{$\phi\left({ }^{\circ}\right)$} \\
\hline & Stress $(\mathrm{MPa})$ & Orientation & & \\
\hline Ertan & 64.4 & $\mathrm{~N} 23^{\circ} \mathrm{E}$ & $\mathrm{N} 6^{\circ} \mathrm{W}$ & 29 \\
\hline Xiaolangdi & 5.0 & $\mathrm{~N} 20^{\circ} \mathrm{E}$ & $\mathrm{N} 10^{\circ} \mathrm{W}$ & 30 \\
\hline Lubuge & 19.0 & $\mathrm{~N} 70^{\circ} \mathrm{W}$ & $\mathrm{N} 45^{\circ} \mathrm{W}$ & 25 \\
\hline Guangzhou Pumped Storage & 12.2 & Nearly EW & $\mathrm{N} 80^{\circ} \mathrm{E}$ & Nearly parallel \\
\hline Xiaowan & 23.0 & $\mathrm{~N} 64^{\circ} \mathrm{W}$ & $\mathrm{S} 140^{\circ} \mathrm{E}$ & 24 \\
\hline Nuozhadu & 8.27 & $\mathrm{~N} 50.1^{\circ}-55.8^{\circ} \mathrm{E}$ & $\mathrm{N} 76^{\circ} \mathrm{E}$ & $20.2-25.9$ \\
\hline
\end{tabular}

and the longitudinal axis of the transformer chamber and the tailrace surge chamber are acute angles, which is beneficial to the stability of the whole underground cavern group.

Fig. 5 plots a large dataset of stress magnitudes versus depth based on national data from typical hydropower projects in China, including the Huangdeng hydropower station, and shows the minimum and maximum envelope lines reported by different researchers (Feng et al., 2000; Xue and Chen, 2006; Zhao et al., 2007; Zhang, 2011; Li et al., 2012; Liu et al., 2014). The $K$ values have been calculated as defined by Brown and Hoek (1978), $K=\left(\sigma_{\mathrm{H}}+\sigma_{\mathrm{h}}\right) /\left(2 \sigma_{\mathrm{V}}\right)$, to compare the envelope lines expressed by scatter points in Fig. 5, and $\sigma_{\mathrm{H}}$ and $\sigma_{\mathrm{h}}$ represent horizontal stresses in two directions of a particular plane, while $\sigma_{\mathrm{V}}$ represents the vertical stress. The four solid scatter points represent the actual in situ stress measurements of the Huangdeng hydropower station. Table 3 shows the relationship among $K_{\mathrm{H}}, K_{\mathrm{h}}$, and depth for the other main hydropower projects in China, defining $K_{\mathrm{H}}=\sigma_{\mathrm{H}} / \sigma_{\mathrm{V}}$ and $K_{\mathrm{h}}=\sigma_{\mathrm{h}} / \sigma_{\mathrm{V}}$. The maximum envelope lines are generally similar, with less data scatter for

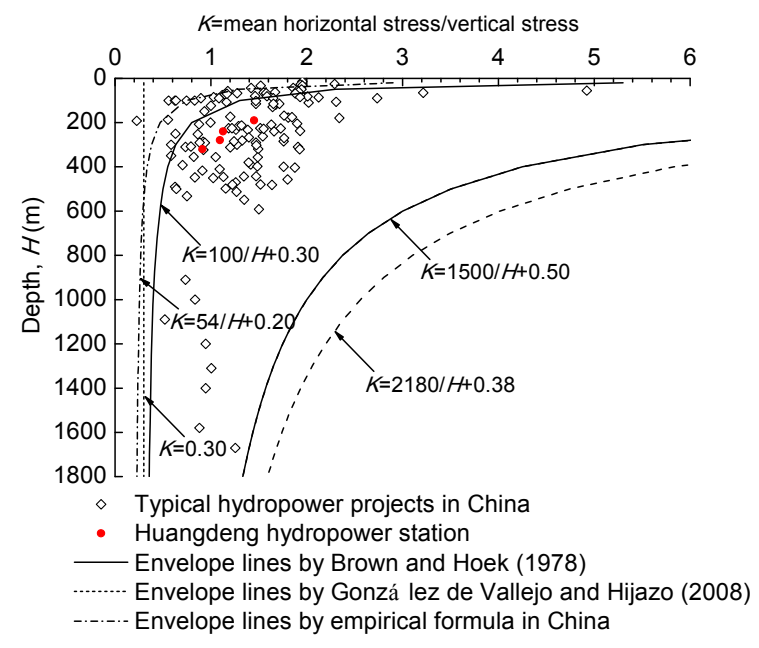

Fig. $5 \mathrm{~K}$-depth relationships based on national data for China

depths greater than $1000 \mathrm{~m}$, with $K$ tending toward 1.0 with depth. The minimum envelope lines show greater discrepancies for depths below $500 \mathrm{~m}$. These results show that at typical depths for most underground excavations, $K$-depth relationships cannot be used in practice. 
Table $3 K$-depth relationships for typical hydropower projects in China

\begin{tabular}{|c|c|c|c|c|}
\hline $\begin{array}{c}\text { Typical } \\
\text { engineering } \\
\text { project }\end{array}$ & $K_{\mathrm{H}}$ & $K_{\mathrm{h}}$ & $K$ & $\begin{array}{c}\text { Depth } \\
\text { (m) }\end{array}$ \\
\hline Three & 2.50 & 2.11 & 2.31 & 106.0 \\
\hline Gorges & 1.42 & 1.10 & 1.26 & 235.0 \\
\hline \multirow{2}{*}{$\begin{array}{l}\text { (Feng et al., } \\
2000)\end{array}$} & 0.70 & 0.55 & 0.63 & 490.0 \\
\hline & 0.52 & 0.52 & 0.52 & 1090.0 \\
\hline \multirow{2}{*}{ Nuozhadu } & 0.81 & 0.30 & 0.55 & 187.4 \\
\hline & 1.77 & 1.00 & 1.39 & 232.8 \\
\hline \multirow{2}{*}{ Longtan } & 1.35 & 1.20 & 1.28 & 67.5 \\
\hline & 2.88 & 0.74 & 1.81 & 177.0 \\
\hline \multirow{3}{*}{ Xiluodu } & 2.09 & 1.17 & 1.63 & 210.0 \\
\hline & 1.41 & 0.44 & 0.92 & 324.0 \\
\hline & 1.57 & 0.69 & 1.13 & 445.0 \\
\hline \multirow{3}{*}{$\begin{array}{l}\text { Jinping I } \\
\text { (Gong et } \\
\text { al., 2010) }\end{array}$} & 0.84 & 0.63 & 0.74 & 910.0 \\
\hline & 1.22 & 0.79 & 1.01 & 1310.0 \\
\hline & 1.58 & 0.93 & 1.26 & 1670.0 \\
\hline \multirow{3}{*}{ Xiaolangdi } & 1.05 & 1.01 & 1.03 & 85.0 \\
\hline & 1.07 & 0.42 & 0.75 & 100.0 \\
\hline & 1.03 & 0.83 & 0.93 & 149.0 \\
\hline \multirow{5}{*}{ Rasiva } & 1.48 & 0.31 & 0.90 & 90.0 \\
\hline & 2.04 & 1.39 & 1.72 & 115.0 \\
\hline & 1.22 & 0.77 & 1.00 & 200.0 \\
\hline & 0.89 & 0.58 & 0.74 & 310.0 \\
\hline & 1.30 & 0.88 & 1.09 & 410.0 \\
\hline \multirow{3}{*}{$\begin{array}{l}\text { Dagang- } \\
\text { shan }\end{array}$} & 1.85 & 0.98 & 1.42 & 390.0 \\
\hline & 1.43 & 0.62 & 1.03 & 450.0 \\
\hline & 1.06 & 0.22 & 0.64 & 500.0 \\
\hline \multirow{5}{*}{ Baihetan } & 1.95 & 0.99 & 1.47 & 290.0 \\
\hline & 1.57 & 1.42 & 1.49 & 320.0 \\
\hline & 1.72 & 1.22 & 1.47 & 442.0 \\
\hline & 1.37 & 1.17 & 1.27 & 513.0 \\
\hline & 1.76 & 1.24 & 1.50 & 591.5 \\
\hline \multirow{7}{*}{$\begin{array}{l}\text { Pubugou } \\
\text { (Xue and } \\
\text { Chen, } \\
\text { 2006) }\end{array}$} & 1.76 & 0.83 & 1.29 & 215.0 \\
\hline & 1.87 & 0.93 & 1.40 & 267.0 \\
\hline & 1.36 & 1.04 & 1.20 & 312.0 \\
\hline & 1.39 & 0.97 & 1.18 & 57.3 \\
\hline & 1.71 & 1.84 & 1.78 & 125.0 \\
\hline & 1.72 & 1.38 & 1.55 & 228.0 \\
\hline & 1.40 & 1.15 & 1.27 & 300.0 \\
\hline
\end{tabular}

\subsection{Numerical calculation model}

Having comprehensively considered many factors, such as the characteristics of topography and geomorphology, an elaborate numerical simulation model was built based on the characteristics of the layout and structure of the actual engineering project. Particular attention was paid to the modeling range, affected zones, and boundary constraint conditions of the Huangdeng underground cavern group. The scope of the computational model was $478 \mathrm{~m}$ in the $x$-direction, $450 \mathrm{~m}$ in the $y$-direction, and $596 \mathrm{~m}$ from the isolated rock-mass, to eliminate the effect of artificial boundary errors on the structure of the underground caverns (Fig. 6). There are more than 104583 nodes and 618027 quadrilateral elements in this numerical calculation model, including five main geological faults, $F_{9}, F_{230-1}, F_{14}, f_{20}$, and $f_{230-1}$, and tuff interlayers $t_{p 230-1}$ located in the underground cavern area.

The Mohr-Coulomb model was adopted in the Abaqus analysis. In the inversion of the in situ stress field, the simulation of land surface denudation mainly entails taking the highest point of the calculated region as a baseline, which is necessary to choose an appropriate region. Gravity stress revises the coefficient parameter of the volume-weight to serve as an influence parameter that is expected to be output; tectonic stress is created by applying the displacement boundary in the computing area. A gradual elastoplastic excavation simulation is adopted to record the denudation effect of unloading. Because roller boundary conditions are reasonable for the pre-excavation process of the in situ stress field inversion (Zhao et al., 2012), the bottom edge constraint is applied for normal constraints, while the outer boundary of the rock formation is considered to be a free boundary (Zhang and Yin, 2014). The

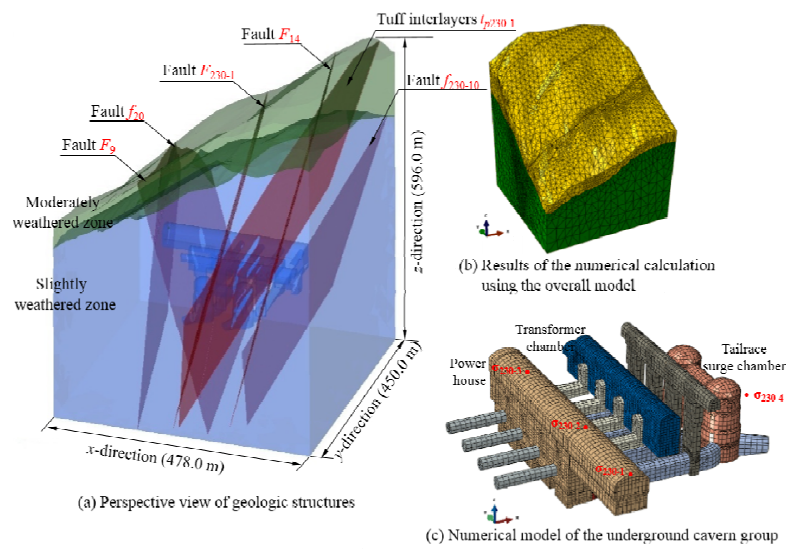

Fig. 6 Numerical simulation model of the Huangdeng underground cavern group 
physical and mechanical properties of the rock-mass used in the numerical experiment, which are taken mainly from the results of previous laboratory tests, are given in Table 4. In other words, the whole process of numerical simulation follows the principle of geometry simulation, constitutive simulation, and stress state simulation.

\subsection{Recognition of the boundary conditions to be determined}

\subsubsection{Process of undetermined parameter recognition}

Based on the coordinate system of the numerical simulation model, the principal stress results from the in situ stress measurements were converted into stress components (Table 5). The SR-DE-SVM method is proposed to obtain optimal values of parameters that best match the modeling prediction with the measured stress data. Specifically, the appropriate boundary conditions for the numerical calculation model, such as the gravity correction coefficient and various tectonic movement patterns, are recognized. SR is used to search for the best parameter system, having a decisive role in the formation process of the in situ stress field, which is expressed using the $C \#$ programing language. Based on the results of SR analysis, the shear structure factors $\tau_{x y}$ and $\tau_{y z}$ were regarded as unsatisfactory results under the boundary conditions. In other words, five undetermined parameters were defined in the inversion analysis, including the gravity correction coefficient $g^{*}$ and other shear structure factors $\tau_{x x}, \tau_{y y}, \tau_{y x}$, and $\tau_{x z}$. Furthermore, the ranges of identification parameters were determined as follows: $g^{*} \in[7.85$, $17.66] \mathrm{m} / \mathrm{s}^{2}, \tau_{x x} \in[0.10,0.25] \mathrm{m}, \tau_{y y} \in[0.00,0.15] \mathrm{m}$, $\tau_{y x} \in[0.25,0.45] \mathrm{m}$, and $\tau_{x z} \in[0.10,0.25] \mathrm{m}$. Finally, 35 training and test samples with the calculated stress components at measured points and undetermined parameters of boundary conditions were created by uniform design $\mathrm{U}_{35}\left(35^{3}\right)$.

\subsubsection{Process of undetermined parameter recognition}

In this section, the results of the proposed DESVM method are verified against the data generated in Section 4.3.1. Taking 30 schemes as training samples and five schemes as test samples, the DE-SVM algorithm can be used to obtain the best parameters of $c$ and $k$ in SVM modeling. After conducting learning and training using the corresponding parameters input from the training samples, a nonlinear mapping model was established between the measured stress of the engineering site and the boundary conditions to be estimated. Fig. 7 shows the forecast effect tests of SVM for five test samples. The tendency is for the predictions by SVM to be close to the stress values

Table 4 Physical properties of the rock-mass applied in the numerical model

\begin{tabular}{lcccccc}
\hline \multicolumn{1}{c}{ Lithology } & $\begin{array}{c}\text { Unit weight } \\
\left(\mathrm{kN} / \mathrm{m}^{3}\right)\end{array}$ & $\begin{array}{c}\text { Elastic } \\
\text { modulus }(\mathrm{GPa})\end{array}$ & $\begin{array}{c}\text { Poisson's } \\
\text { ratio }\end{array}$ & $\begin{array}{c}\text { Cohesion } \\
\text { strength }(\mathrm{MPa})\end{array}$ & $\begin{array}{c}\text { Fiction } \\
\text { angle }\left({ }^{\circ}\right)\end{array}$ & $\begin{array}{c}\text { Dilatancy } \\
\text { angle }\left(^{\circ}\right)\end{array}$ \\
\hline Moderately weathered zone & 26.3 & 12.0 & 0.27 & 1.1 & 47.8 & 28.8 \\
Slightly weathered zone & 26.5 & 13.0 & 0.26 & 1.2 & 50.2 & 33.5 \\
Tuff interlayers $t_{p 230-1}$ & 25.5 & 8.0 & 0.29 & 0.9 & 42.0 & 15.0 \\
Fault $F_{9}$ & 25.0 & 2.0 & 0.30 & 0.2 & 35.0 & 8.3 \\
Fault $f_{20}$ & 25.5 & 6.0 & 0.28 & 0.3 & 42.0 & 10.4 \\
Fault $F_{230-1}$ & 25.0 & 2.0 & 0.30 & 0.1 & 26.6 & 6.6 \\
Fault $F_{14}$ & 25.0 & 2.0 & 0.30 & 0.2 & 32.0 & 7.5 \\
Fault $f_{230-10}$ & 25.5 & 6.0 & 0.28 & 0.3 & 38.7 & 9.7 \\
\hline
\end{tabular}

Table 5 Stress components of in situ stress measurement in the underground cavern zone

\begin{tabular}{cccccccc}
\hline \multirow{2}{*}{ Test point } & \multirow{2}{*}{ Location } & \multicolumn{5}{c}{ Stress component (MPa) } \\
\cline { 3 - 7 } & & $\sigma_{x}$ & $\sigma_{y}$ & $\sigma_{z}$ & $\tau_{x y}$ & $\tau_{x z}$ & $\tau_{y z}$ \\
\hline$\sigma_{230-1}$ & PD230: 105.0-129.5 m; depth: 320 m & -4.14 & -3.11 & -3.98 & 1.20 & 2.28 & -1.01 \\
$\sigma_{230-2}$ & PD230: 198.7-217.0 m; depth: $240 \mathrm{~m}$ & -6.14 & -8.64 & -6.56 & 1.74 & 3.04 & -2.25 \\
$\sigma_{230-3}$ & PD230: 307.0-324.0 m; depth: $190 \mathrm{~m}$ & -11.79 & -4.18 & -5.50 & 4.21 & 2.22 & -2.30 \\
$\sigma_{230-4}$ & Inferior branch of PD230; depth: $280 \mathrm{~m}$ & -11.24 & -6.14 & -7.93 & 2.60 & 1.73 & -1.55 \\
\hline
\end{tabular}



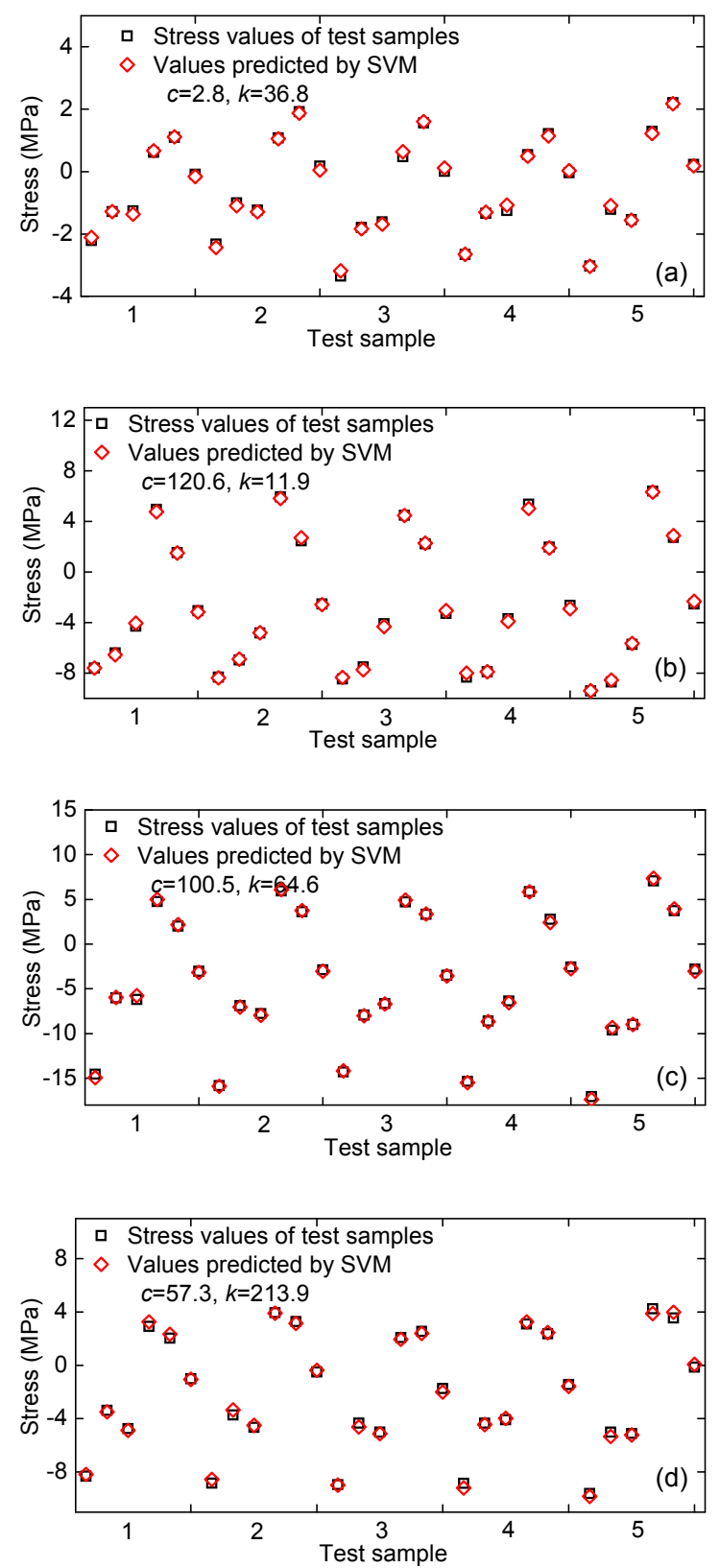

Fig. 7 Forecast effect tests of measured points by SVM

(a) $\sigma_{230-1} ;$; (b) $\sigma_{230-2}$; (c) $\sigma_{230-3}$; (d) $\sigma_{230-4}$

of the testing samples, meaning that the nonlinear relationship between the measured stress and unknown boundary conditions can be reflected by a nonlinear model based on DE-SVM.

\subsubsection{Definition of boundary conditions}

In this section, the optimal values of the parameters from the measured stress data obtained using the SR-DE-SVM nonlinear reflection model are compared with those obtained by an MLR analysis method and an ANN method to estimate the in situ stress field for the actual underground cavern at the Huangdeng hydropower station. Fig. 8 shows the three algorithms used to explore the boundary conditions.

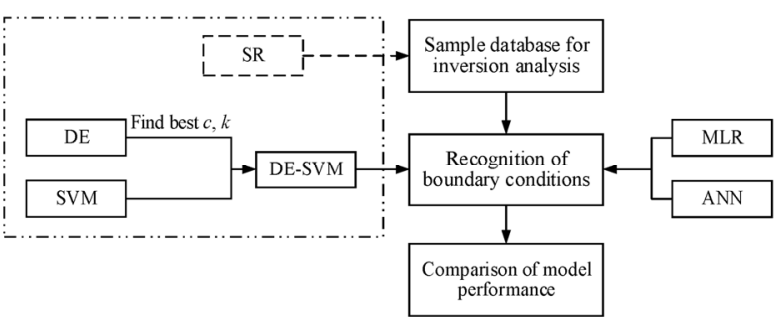

Fig. 8 Various algorithms used for boundary condition exploration

First, a nonlinear model based on DE-SVM was introduced to the objective function, Eq. (12), to explore the best matched values of the boundary conditions. Based on the results of SR, the initial values of five optimization variables were set as follows: $g^{*}=$ $11.78 \mathrm{~m} / \mathrm{s}^{2}, \tau_{x x}=0.18 \mathrm{~m}, \tau_{y y}=0.08 \mathrm{~m}, \tau_{y x}=0.35 \mathrm{~m}$, and $\tau_{x z}=0.15 \mathrm{~m}$. The population size $N_{\mathrm{p}}$ was 20 , and the maximum number of iterations $G_{\max }$ was 500 . The value of the scaling factor $F$ strongly influences the rate of convergence and the crossover constant CR in the optimized recognition process, both of which are determined by the user. Fortunately, the convergence value tends to be stable, which means that there is almost no difference for different values of $F$ and $\mathrm{CR}$. When the DE curve became astringed, the optimal undetermined parameters were obtained (Table 6). The inversion results of the MLR and ANN methods are also presented for comparison.

Because of the limited number of measuring points, the MLR and ANN methods, which are widely applied, were selected to provide a reasonable comparison with the SR-DE-SVM algorithm. The procedure used in this study showed superior accuracy and efficiency in the inversion analysis of the in situ stress field. To verify the rationality of the identification parameters, the obtained boundary conditions of different algorithms were input into a numerical calculation model for elastic-plastic finite element analysis. Tables 7 and 8 show the computational stress components at four monitoring points. 
Table 6 Stress components of the in situ stress measurement in the underground cavern zone

\begin{tabular}{cccccccc}
\hline \multirow{2}{*}{ Algorithm } & \multicolumn{7}{c}{ Parameter to be recognized } \\
\cline { 2 - 8 } & $\tau_{x x}(\mathrm{~mm})$ & $\tau_{y y}(\mathrm{~mm})$ & $\tau_{x y}(\mathrm{~mm})$ & $\tau_{y x}(\mathrm{~mm})$ & $\tau_{x z}(\mathrm{~mm})$ & $\tau_{y z}(\mathrm{~mm})$ & $g^{*}\left(\mathrm{~m} / \mathrm{s}^{2}\right)$ \\
\hline MLR & 23.4 & 15.0 & -9.3 & 25.6 & -15.0 & 16.8 & 14.7 \\
ANN & 19.2 & 13.6 & -9.8 & 36.2 & -6.0 & 14.3 & 13.5 \\
SR-DE-SVM & 24.5 & 12.4 & & 38.2 & & 18.6 & 15.9 \\
\hline
\end{tabular}

Table 7 Computational stress components at four monitoring points

\begin{tabular}{cccccccc}
\hline \multirow{2}{*}{ Test point } & \multirow{2}{*}{ Algorithm } & \multicolumn{7}{c}{ Stress component (MPa) } \\
\cline { 3 - 7 } & & $\sigma_{x}$ & $\sigma_{y}$ & $\sigma_{z}$ & $\tau_{x y}$ & $\tau_{x z}$ & $\tau_{y z}$ \\
\hline \multirow{5}{*}{$\sigma_{230-1}$} & Monitored & -4.14 & -3.11 & -3.98 & 1.20 & 2.28 & -1.01 \\
& MLR & -6.03 & -4.49 & -3.67 & 1.02 & 1.92 & -0.24 \\
& ANN & -4.89 & -3.72 & -3.87 & 1.09 & 1.99 & -0.57 \\
& SR-DE-SVM & -4.47 & -2.93 & -4.08 & 1.32 & 1.98 & -0.99 \\
\hline \multirow{5}{*}{$\sigma_{230-2}$} & Monitored & -6.14 & -8.64 & -6.56 & 1.74 & 3.04 & -2.25 \\
& MLR & -9.53 & -11.02 & -6.30 & 1.56 & 2.87 & -2.92 \\
& ANN & -8.35 & -10.00 & -6.48 & 1.69 & 3.09 & -2.56 \\
& SR-DE-SVM & -6.02 & -8.89 & -6.21 & 1.42 & 3.36 & -2.47 \\
\hline \multirow{5}{*}{$\sigma_{230-3}$} & Monitored & -11.79 & -4.18 & -5.50 & 4.21 & 2.22 & -2.30 \\
& MLR & -13.43 & -5.57 & -7.98 & 2.10 & 2.95 & -2.47 \\
& ANN & -12.58 & -4.66 & -6.65 & 3.20 & 2.56 & -2.44 \\
& SR-DE-SVM & -12.05 & -3.91 & -6.00 & 4.49 & 2.42 & -2.63 \\
\hline \multirow{6}{*}{$\sigma_{230-4}$} & Monitored & -11.24 & -6.14 & -7.93 & 2.60 & 1.73 & -1.55 \\
& MLR & -10.05 & -7.33 & -6.65 & 0.35 & 2.40 & -1.35 \\
& ANN & -10.60 & -6.90 & -7.45 & 3.33 & 1.08 & -1.52 \\
& SR-DE-SVM & -11.49 & -6.49 & -7.96 & 2.03 & 1.92 & -1.38 \\
\hline
\end{tabular}

Table 8 Computational stress components at selected nodes

\begin{tabular}{|c|c|c|c|c|c|c|c|c|}
\hline \multirow{2}{*}{ No. } & \multirow{2}{*}{$\begin{array}{l}\text { Nodes } \\
\text { number }\end{array}$} & \multirow{2}{*}{ Algorithm } & \multicolumn{6}{|c|}{ Stress component $(\mathrm{MPa})$} \\
\hline & & & $\sigma_{x}$ & $\sigma_{y}$ & $\sigma_{z}$ & $\tau_{x y}$ & $\tau_{x z}$ & $\tau_{y z}$ \\
\hline \multirow{3}{*}{$\mathrm{A}$} & \multirow{3}{*}{103052} & MLR & -7.74 & -8.48 & -4.73 & -0.17 & 3.73 & -1.80 \\
\hline & & ANN & -8.81 & -9.05 & -7.00 & -0.31 & 3.58 & -2.20 \\
\hline & & SR-DE-SVM & -8.10 & -8.32 & -5.37 & -0.25 & 3.21 & -1.93 \\
\hline \multirow{3}{*}{$\mathrm{B}$} & \multirow{3}{*}{102432} & MLR & -4.62 & -6.10 & -4.34 & 1.71 & 1.61 & -0.59 \\
\hline & & ANN & -5.45 & -7.49 & -4.82 & 1.86 & 1.69 & -0.32 \\
\hline & & SR-DE-SVM & -4.82 & -7.20 & -4.79 & 1.81 & 1.65 & -0.60 \\
\hline \multirow{3}{*}{$\mathrm{C}$} & \multirow{3}{*}{25786} & MLR & -14.08 & -9.28 & -10.47 & 4.65 & 2.39 & -3.06 \\
\hline & & ANN & -14.53 & -10.22 & -10.47 & 4.85 & 2.36 & -3.16 \\
\hline & & SR-DE-SVM & -14.20 & -8.71 & -10.44 & 4.76 & 2.38 & -3.07 \\
\hline \multirow{3}{*}{$\mathrm{D}$} & \multirow{3}{*}{31435} & MLR & -10.49 & -7.88 & -8.27 & 0.46 & 2.57 & -1.66 \\
\hline & & ANN & -10.56 & -7.94 & -8.27 & 0.44 & 2.51 & -1.66 \\
\hline & & SR-DE-SVM & -10.95 & -7.83 & -8.28 & 0.49 & 2.56 & -1.74 \\
\hline \multirow{3}{*}{$\mathrm{E}$} & \multirow{3}{*}{102811} & MLR & -15.07 & -10.25 & -11.64 & 8.84 & 1.82 & -3.01 \\
\hline & & ANN & -16.88 & -10.68 & -13.82 & 8.94 & 1.57 & -5.25 \\
\hline & & SR-DE-SVM & -15.58 & -10.68 & -12.56 & 8.31 & 1.82 & -4.44 \\
\hline \multirow{3}{*}{$\mathrm{F}$} & \multirow{3}{*}{102338} & MLR & -10.55 & -8.44 & -9.51 & 0.45 & -0.45 & 0.17 \\
\hline & & ANN & -12.68 & -9.47 & -10.75 & 0.30 & -0.42 & 0.16 \\
\hline & & SR-DE-SVM & -11.63 & -9.35 & -10.3 & 0.33 & -0.37 & 0.15 \\
\hline
\end{tabular}


Fig. 9 compares the normal stress at each of the four monitoring points with three different results respectively, while Fig. 10 compares the normal stress at each of the six selected nodes A-F, which were chosen on Pile No. K0+070 m cross section in the $x$-direction (Fig. 11).

The results of each algorithm are in good agreement with the monitored in situ stresses, especially for the ANN and SR-DE-SVM methods. Furthermore, note that for each of the six selected points, the results of all the algorithms are very consistent. Thus, the efficiency and error comparison of MLR, ANN, and SR-DE-SVM in Table 9 shows that the three methods have a similar time cost for model
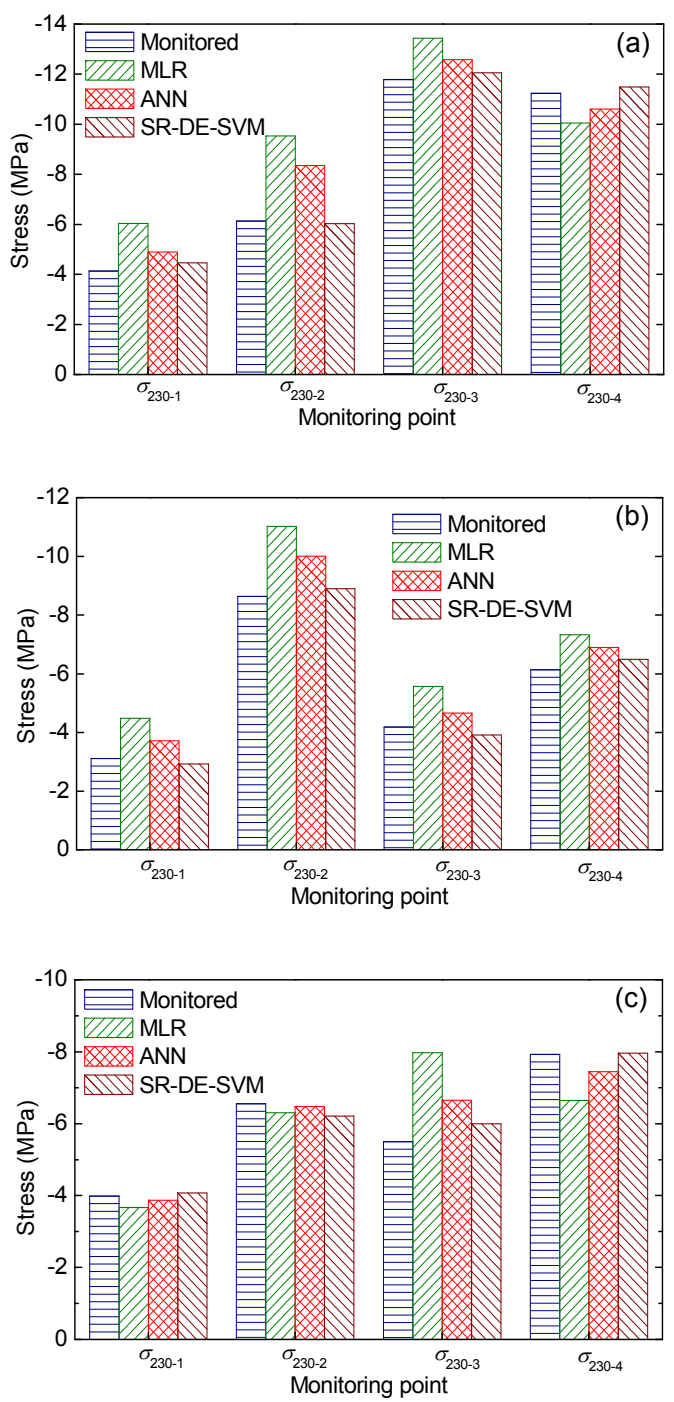

Fig. 9 Comparison of normal stress at each of the four monitoring points: (a) $\sigma_{x}$; (b) $\sigma_{y}$; (c) $\sigma_{z}$
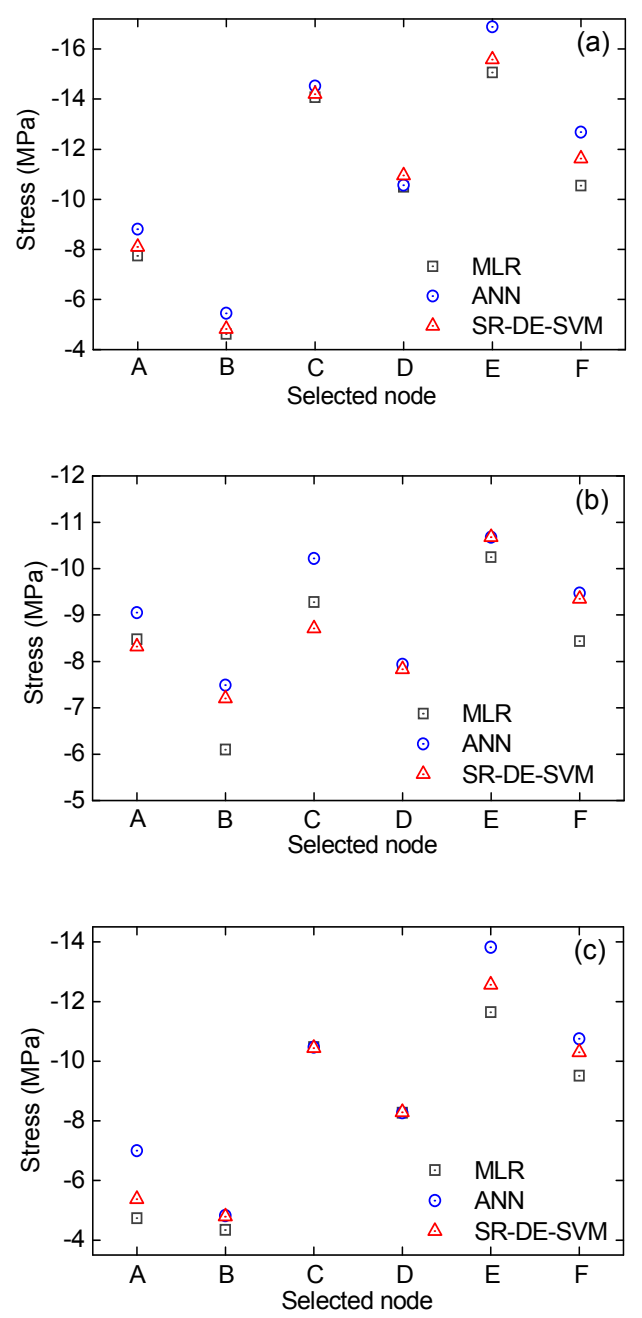

Fig. 10 Comparison of normal stress at each selected node: (a) $\sigma_{x}$; (b) $\sigma_{y}$; (c) $\sigma_{z}$

building. However, the computing analysis time of the SR-DE-SVM algorithm was only 4489 s, compared with $6236 \mathrm{~s}$ for MLR and $5816 \mathrm{~s}$ for ANN due to the reduction in the parameters of boundary conditions to be applied greatly improving efficiency. More importantly, the model performance of SRDE-SVM appears to provide the best match, with a maximum absolute error of only $1.50 \mathrm{MPa}$ and a maximum relative error of only $9.09 \%$.

\subsection{Distribution analysis of the in situ stress field}

The distribution of the in situ stress field at the Huangdeng engineering site was successfully obtained after optimal boundary conditions from the SR-DE-SVM algorithm were input into a numerical 
calculation model for elastic-plastic finite element analysis.

4.4.1 Characteristics of vertical subsidence and horizontal displacement

Based on the power house excavation from step 1 through step 6, the curves of vertical subsidence (Fig. 12) and horizontal displacements (Fig. 13) in different excavation stages are shown to facilitate the comparative study under different stress fields, including an ideal gravity stress field and the estimated and practical in situ stress field.

In the ideal gravity stress field, the subsidence curves of the selected analysis baseline in the Huangdeng numerical calculation model are smooth and symmetrical (Fig. 12a). With increasing excavation depth, the subsidence increases markedly, and the maximum subsiding center migrates slowly to the longitudinal axis of the power house.

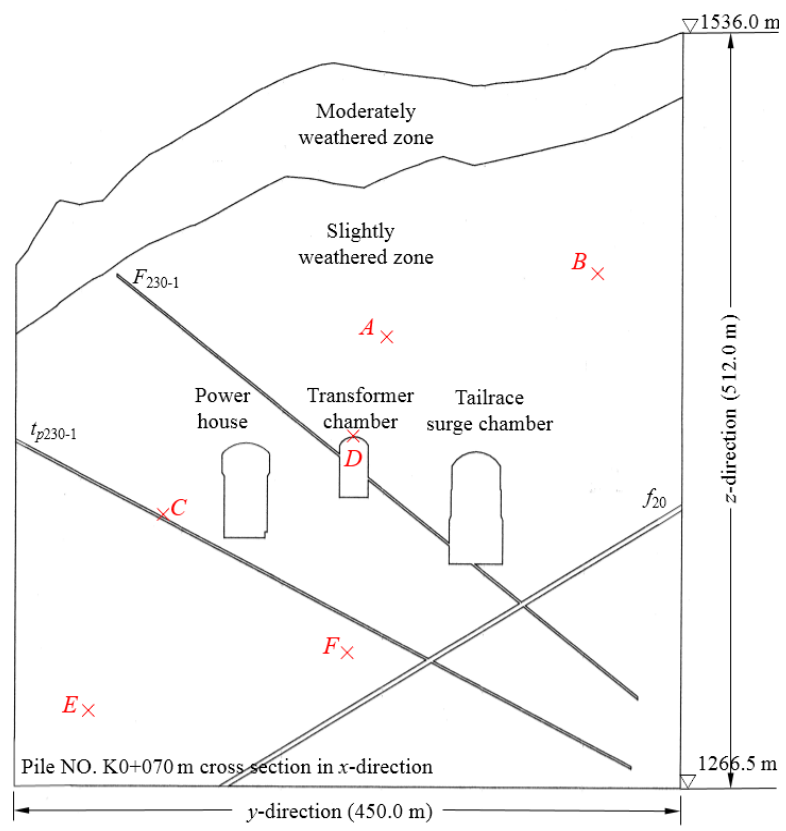

Fig. 11 Selected nodes on Pile No. K0+070 m cross section in the $x$-direction
In the estimated and practical in situ stress field, the subsidence curves of the selected analysis baseline show different characteristics at different excavation stages (Fig. 12b). In the initial stage of singlelevel excavation, although the subsidence curves are similar, the maximum subsidence value is only $72.8 \%$ of those in the gravity stress field. In the subsequent excavation steps, the maximum subsiding center gradually migrates from the primary longitudinal axis to the upstream side of the power house (the left side of the coordinate) with excavation depth during the excavation process. Moreover, the subsidence values are all larger than those of each excavation step in the ideal gravity stress field. This means that the migration rate is larger in the estimated and practical in situ stress field than in the

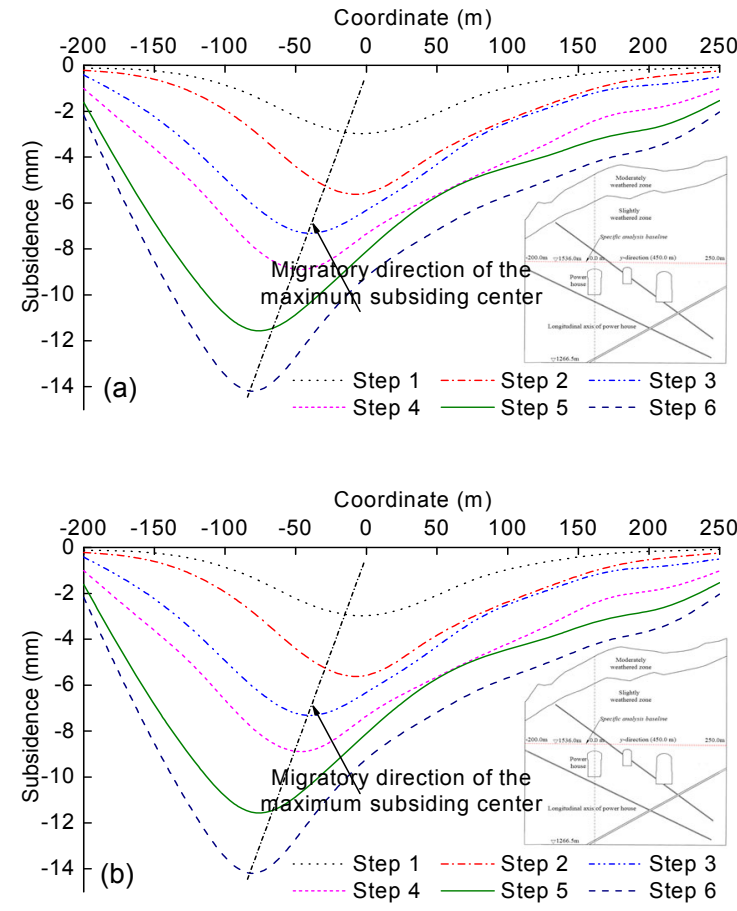

Fig. 12 Curves of subsidence induced by excavation in an ideal gravity stress field (a) and the estimated and practical in situ stress field (b)

Table 9 Model efficiency and error comparison in the recognition of boundary conditions

\begin{tabular}{cccccccc}
\hline \multirow{2}{*}{ Algorithm } & \multicolumn{4}{c}{ Efficiency (s) } & \multicolumn{2}{c}{ Error } \\
\cline { 2 - 4 } \cline { 6 - 7 } & Build & Train & Test & Computing analysis & & Max. absolute error (MPa) & Max. relative error (\%) \\
\hline MLR & 360 & 6.62 & 0.01 & 6236 & & 3.39 & 55 \\
ANN & 410 & 0.92 & 0.02 & 5816 & 2.21 & 36 \\
SR-DE-SVM & 384 & 0.90 & 0.19 & 4489 & 0.50 & 9.1 \\
\hline
\end{tabular}


gravity stress field, and the maximum subsidence increases $21.7 \%$ compared with the latter. Thus, the tectonic stress field is closely linked to the displacement field as well as the stability of the surrounding rock-mass in the engineering site, which appears to be non-negligible.

The horizontal displacements changed at different stages of excavation in different stress fields (Fig. 13). In general, the horizontal displacements of the downstream side of the power house (the right side of the coordinate) were much larger than those of the upstream side in the ideal gravity stress field. Furthermore, the maximum horizontal displacement of the downstream side of the power house was 2.24 times that of the upstream side in the gravity stress field (Fig. 13a). In contrast, the maximum horizontal displacement of the downstream side of the power house was only 1.59 times that of the upstream side in Fig. 13b, but the horizontal displacement and its distribution range expanded prominently because of the occurrence of the practical tectonic stress field.

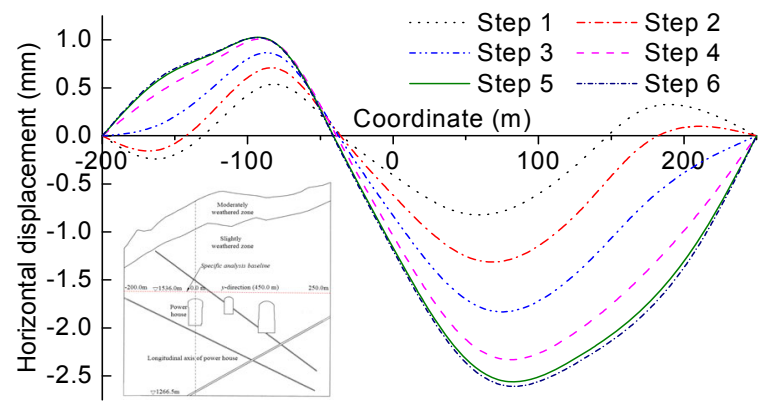

(a)

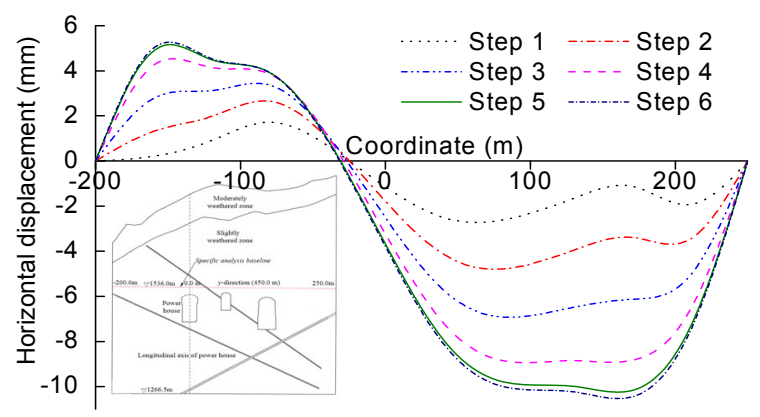

(b)

Fig. 13 Curves of the horizontal displacement induced by excavation in an ideal gravity stress field (a) and the estimated and practical in situ stress field (b)
4.4.2 Characteristics of in situ stress in the area of the power house along its depth

Taking the power house as an example, Fig. 14 shows the distribution curves of the normal stresses $\sigma_{\mathrm{H}}, \sigma_{\mathrm{h}}$, and $\sigma_{\mathrm{V}}$ of the selected analysis baseline (the longitudinal axis of the power house) along its depth. With increasing rock-mass depth, the normal stresses $\sigma_{\mathrm{H}}, \sigma_{\mathrm{h}}$, and $\sigma_{\mathrm{V}}$ increase linearly in the area of the underground rock-mass without geological faults as well as in those with tuff interlayers incised. In detail, $\sigma_{\mathrm{H}}$ ranges from 10.5 $\mathrm{MPa}$ to $15.1 \mathrm{MPa}$ in the buried depth range of the Huangdeng underground cavern group, while $\sigma_{\mathrm{h}}$ is between $7.45 \mathrm{MPa}$ and 11.3 MPa, and $\sigma_{\mathrm{V}}$ is between $7.36 \mathrm{MPa}$ and 12.0 MPa. Thus, the change rate of the vertical stress $\sigma_{\mathrm{V}}$ seems to be more sensitive to the increase in the rock-mass depth. Around the surface area of the rock-mass, the in situ stress follows the size relationship of each normal stress $\sigma_{\mathrm{V}}<\sigma_{\mathrm{h}}<\sigma_{\mathrm{H}}$, but when the buried depth exceeds a certain value of $200 \mathrm{~m}$, the relationship changes to $\sigma_{\mathrm{h}}<\sigma_{\mathrm{V}}<\sigma_{\mathrm{H}}$.

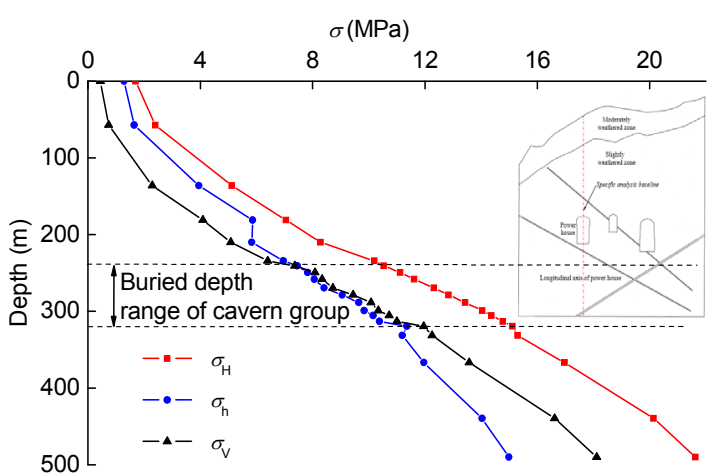

Fig. 14 Distribution of in situ stress in the area of the power house along its depth

Furthermore, Fig. 15 shows the distribution curves of $K_{\mathrm{H}}$ and $K_{\mathrm{h}}$ of the selected analysis baseline (the longitudinal axis of the power house) along its depth. $K_{\mathrm{H}}$ and $K_{\mathrm{h}}$ decrease gradually with increasing rock-mass depth, with a particularly sharp decrease near the surface of the rock-mass. The decrease rates of $K_{\mathrm{H}}$ and $K_{\mathrm{h}}$ are relatively stable in the buried depth range of the Huangdeng underground cavern group, with $K_{\mathrm{H}} \in(1.26,1.43)$, and $K_{\mathrm{h}} \in(0.94,1.01)$.

$\sigma_{\mathrm{H}}$ ranges from $10.5 \mathrm{MPa}$ to $15.1 \mathrm{MPa}$ in the buried depth range of the Huangdeng underground 
cavern group, while $\sigma_{\mathrm{h}}$ and $\sigma_{\mathrm{V}}$ are between $7.45 \mathrm{MPa}$ and 11.3 MPa, and between 7.36 $\mathrm{MPa}$ and 12.0 MPa, respectively. Thus, the change rate of the vertical stress $\sigma_{\mathrm{V}}$ seems to be more sensitive to the increase in the rock-mass depth. The influence mechanism of the tectonic movements to the in situ stress field is more complicated closer to the surface of the rockmass, which ultimately results in the instability of $K$. Therefore, prioritizing $K$ for a rock-mass whose buried depth exceeds $200 \mathrm{~m}$, the function of the optimum regression curve is reasonably expressed by the formula $K=105 / H+0.80$, which is highly consistent with the relevant results of Zhao et al. (2007).

\section{Validation tests: Nuozhadu underground cavern groups}

Validation tests were conducted by comparing the results produced by the SR-DE-SVM algorithm and the measured in situ stresses in the Nuozhadu underground cavern groups. The in situ measurements

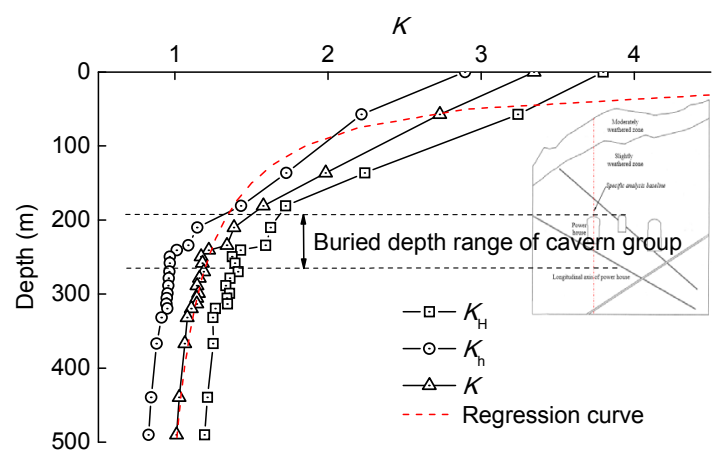

Fig. 15 Distribution of $K$ in the area of the power house along its depth of the Nuozhadu underground cavern groups were made by the Hydro-China Kunming Engineering Corporation. As the measured in situ stresses show (Table 10), the stress level is low in general, because the buried depth of the underground cavern is not very deep. The magnitude and direction of in situ stress are influenced mainly by the geological structure, topography of the engineering area, and the gravity stress field. The numerical analysis was simulated using the SR-DE-SVM algorithm in the Abaqus codes. Table 10 compares the measured in situ stresses with results produced by the SR-DESVM algorithm in the Nuozhadu underground cavern group. Fig. 16 compares the normal stress at each of the four monitoring points in the Nuozhadu underground cavern group intuitively. The results demonstrate high precision of the in situ stress field in the Nuozhadu underground cavern area, which means that the in situ stress distribution within the engineering area can be estimated effectively using the SR-DE-SVM algorithm.

\section{Conclusions}

Due to the complexity and importance of the in situ stress field, it is necessary to learn about the magnitude and direction of an in situ stress field for any underground project according to its specific geological conditions. The SR-DE-SVM algorithm, which is a nonlinear global optimization method combining SR, DE, SVM, and numerical analysis techniques, was presented for estimating the in situ stress in the rock-mass. Through the example of the Huangdeng hydropower station, the SR-DE-SVM

Table 10 Comparison between the measured in situ stresses and results produced by the SR-DE-SVM algorithm in the Nuozhadu underground cavern group

\begin{tabular}{ccccccccc}
\hline \multirow{2}{*}{$\begin{array}{c}\text { Test } \\
\text { point }\end{array}$} & Vertical & \multirow{2}{*}{ Algorithm } & \multicolumn{5}{c}{ Stress component (MPa) } \\
\cline { 4 - 8 }$\sigma_{204-302}$ & 232.8 & Monitored & $\sigma_{x}$ & $\sigma_{y}$ & $\sigma_{z}$ & $\tau_{x y}$ & $\tau_{x z}$ & $\tau_{y z}$ \\
& & SR-DE-SVM & -4.34 & -7.72 & -4.36 & -1.61 & -2.86 & 2.46 \\
$\sigma_{204-502}$ & \multirow{2}{*}{207.3} & Monitored & -0.93 & -5.98 & -3.95 & 2.35 & -2.00 & 0.65 \\
& & SR-DE-SVM & -0.78 & -5.10 & -4.30 & 3.22 & -1.79 & 0.51 \\
$\sigma_{412-215}$ & \multirow{2}{*}{187.4} & Monitored & -1.62 & -4.37 & -5.40 & 2.36 & -2.93 & 2.57 \\
& & SR-DE-SVM & -1.67 & -4.46 & -5.17 & 2.09 & -2.13 & 2.34 \\
$\sigma_{412-380}$ & \multirow{2}{*}{192.4} & Monitored & -0.52 & -2.59 & -6.89 & 0.84 & -0.94 & 1.70 \\
& & SR-DE-SVM & -0.49 & -2.72 & -7.01 & 0.86 & -0.90 & 1.76 \\
\hline
\end{tabular}



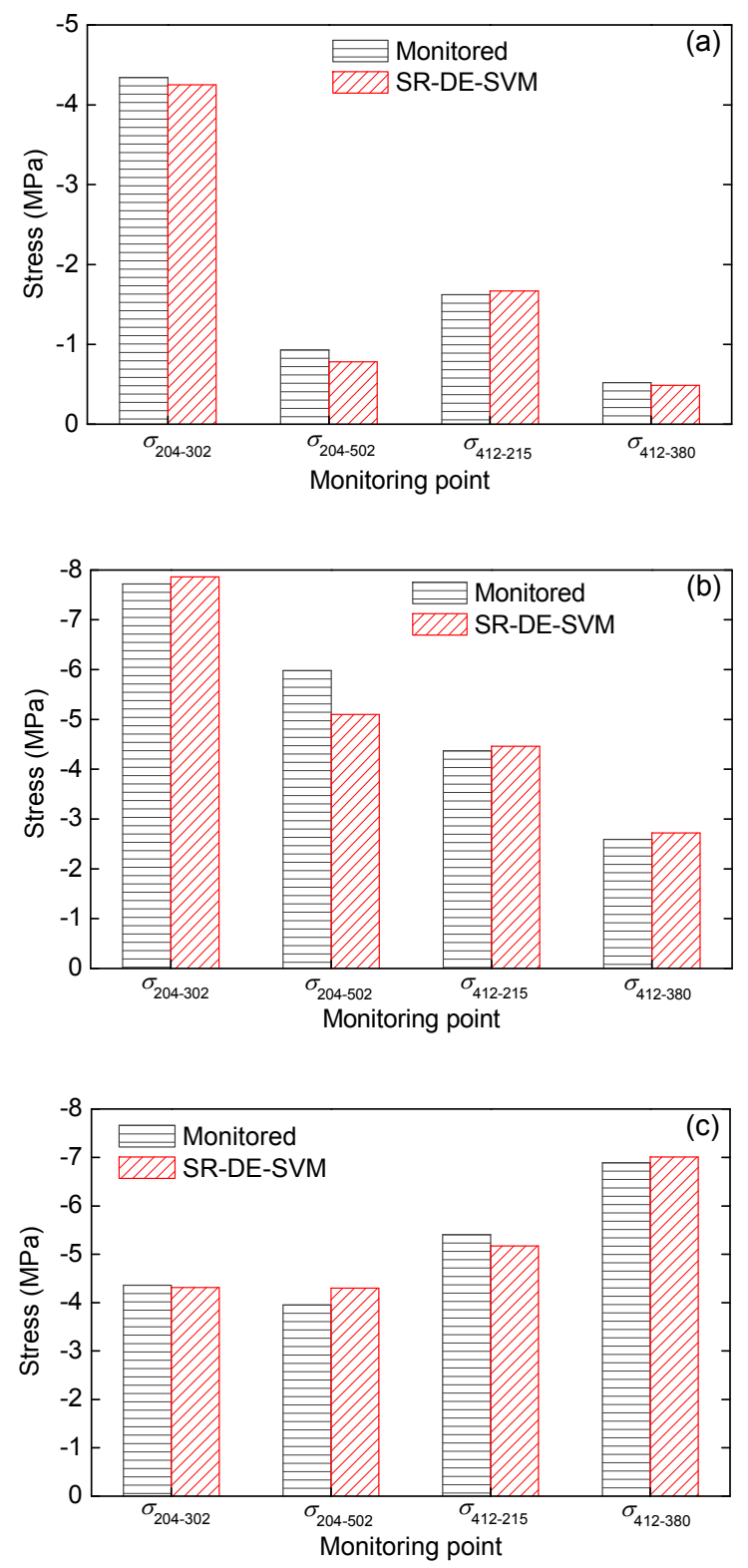

Fig. 16 Comparison of each normal stress at each of the four monitoring points in the Nuozhadu underground cavern group: (a) $\sigma_{x}$; (b) $\sigma_{y}$; (c) $\sigma_{z}$

approach was shown to maintain a consistently high solution accuracy for in situ stress estimation, particularly compared with two contemporary approaches, namely, the MLR method and the ANN surrogate direct inversion approach.

With increasing excavation depth, the subsidence trough maintains a single subsiding center throughout excavation in the gravity stress field. However, in the high-level tectonic stress field, the maximum subsiding center migrates gradually from the primary longitudinal axis to the upstream side of the power house with excavation depth, and the horizontal displacement and its distribution range expand markedly because of the occurrence of the practical tectonic stress field.

In the Huangdeng underground cavern group, the in situ stress is moderate and originates mainly from gravity and the geological tectonic stress field. According to the finite element analysis, the category of the surrounding rocks does not have a serious effect on the in situ stress field at the engineering site. With increasing rock-mass depth, the normal stresses increase linearly in the area of the underground rock-mass without geological faults and tuff interlayers crossed over in areas.

Validation tests were conducted by comparing the results produced by the SR-DE-SVM algorithm with the measured in situ stresses in the Nuozhadu underground cavern groups. The tests showed that the methodology described provides attractive tools to represent the nonlinear relations between boundary conditions and in situ stresses in the rock-mass and may be applied to other rock-masses to model the in situ stress field. This method can clarify the dominant cause of the formation of in situ stress specific to various practical projects to obtain an approximate solution that can provide in situ stress information for the design of dams and tunnels.

\section{References}

Brown, E.T., Hoek, E., 1978. Trends in relationships between measured in-situ stresses and depth. International Journal of Rock Mechanics and Mining Sciences \& Geomechanics Abstracts, 15(4):211-215. http://dx.doi.org/10.1016/0148-9062(78)91227-5

Cheng, M.Y., Hoang, N.D., Wu, Y.W., 2013. Hybrid intelligence approach based on LS-SVM and differential evolution for construction cost index estimation: a Taiwan case study. Automation in Construction, 35:306313. http://dx.doi.org/10.1016/j.autcon.2013.05.018

Feng, X.T., Zhang, Z., Sheng, Q., 2000. Estimating mechanical rock mass parameters relating to the three gorges project permanent shiplock using an intelligent displacement back analysis method. International Journal of Rock Mechanics and Mining Sciences, 37(7): 1039-1054. 
http://dx.doi.org/10.1016/S1365-1609(00)00035-6

Gong, M., Qi, S., Liu, J., 2010. Engineering geological problems related to high geo-stresses at the Jinping I Hydropower Station, Southwest China. Bulletin of Engineering Geology and the Environment, 69(3):373380 . http://dx.doi.org/10.1007/s10064-010-0267-1

González de Vallejo, L.I., Hijazo, T., 2008. A new method of estimating the ratio between in situ rock stresses and tectonics based on empirical and probabilistic analyses. Engineering Geology, 101(3-4):185-194. http://dx.doi.org/10.1016/j.enggeo.2008.05.003

Grossberg, S., 1988. Nonlinear neural networks: principles, mechanisms, and architectures. Neural Networks, 1(1): 17-61. http://dx.doi.org/10.1016/0893-6080(88)90021-4

Guo, H.Z., Ma, Q.C., Xue, X.C., et al., 1983. The analytical method of the initial stress field for rock masses. Chinese Journal of Geotechnical Engineering, 5(3):6475 (in Chinese).

Guo, M.W., Li, C.G., Wang, S.L., et al., 2008. Study on inverse analysis of 3-D initial geostress field with optimized displacement boundaries. Rock and Soil Mechanics, 29(5):1269-1274 (in Chinese).

Hijazo, T., González de Vallejo, L.I., 2012. In-situ stress amplification due to geological factors in tunnels: the case of Pajares tunnels, Spain. Engineering Geology, 137-138:13-20.

http://dx.doi.org/10.1016/j.enggeo.2012.03.007

Jiang, A., Zhao, H., Jiang, S., 2013. Study on 3D intelligent back analysis of tunnel based on DE-SVM. Chinese Journal of Underground Space and Engineering, 9(4): 765-770 (in Chinese).

Jiang, Q., Feng, X.T., Chen, J.L., et al., 2008. Nonlinear inversion of 3D initial geostress field in Jinping II Hydropower Station region. Rock and Soil Mechanics, 29(11):3003-3010 (in Chinese).

Kartam, N., Flood, I., Garrett, J.H., 1997. Artificial Neural Networks for Civil Engineers: Fundamentals and Applications. American Society of Civil Engineers, New York, USA.

Li, Y.S., Yin, J.M., Chen, J.P., et al., 2012. Analysis of 3D insitu stress field and query system's development based on visual BP neural network. Procedia Earth and Planetary Science, 5:64-69. http://dx.doi.org/10.1016/j.proeps.2012.01.011

Liu, Y., Li, H., Luo, C., et al., 2014. In situ stress measurements by hydraulic fracturing in the western route of south to north water transfer project in China. Engineering Geology, 168:114-119. http://dx.doi.org/10.1016/j.enggeo.2013.11.008

Mckinnon, S., 2001. Analysis of stress measurements using a numerical model methodology. International Journal of
Rock Mechanics and Mining Sciences, 38(5):699-709. http://dx.doi.org/10.1016/S1365-1609(01)00037-5

Qin, Z., Liu, C., Zhao, Z., et al., 2008. Back analysis of inintial ground stress by 3D-FSM considering influence of terrain and tectonic stress. Rock and Soil Mechanics, 7:027 (in Chinese).

Saati, V., Mortazavi, A., 2011. Numerical modelling of in situ stress calculation using borehole slotter test. Tunnelling and Underground Space Technology, 26(1):172-178. http://dx.doi.org/10.1016/j.tust.2010.07.002

Samui, P., Kim, D., Aiyer, B.G., 2015. Pullout capacity of small ground anchor: a least square support vector machine approach. Journal of Zhejiang UniversitySCIENCE A (Applied Physics \& Engineering), 16(4): 295-301. http://dx.doi.org/10.1631/jzus.A1200260

Xing, B., Zhang, K., Sun, S., et al., 2015. Emotion-driven Chinese folk music-image retrieval based on DE-SVM. Neurocomputing, 148:619-627. http://dx.doi.org/10.1016/j.neucom.2014.08.007

$\mathrm{Xu}$, R.Q., 2000. The GA-ANN method for determining calculation parameters for deep excavation. Journal of Zhejiang University-SCIENCE, 1(4):408-413. http://dx.doi.org/10.1631/jzus.2000.0408

Xue, L., Chen, S., 2006. Two-stage analysis of geostress field for underground chamber area of Pubugou project. Chinese Journal of Rock Mechanics and Engineering, 25(9):1881-1886 (in Chinese).

Zhang, L., Yue, Z., Yang, Z., et al., 2006. A displacementbased back-analysis method for rock mass modulus and horizontal in situ stress in tunneling-illustrated with a case study. Tunnelling and Underground Space Technology, 21(6):636-649.

http://dx.doi.org/10.1016/j.tust.2005.12.001

Zhang, S., Yin, S., 2014. Determination of in situ stresses and elastic parameters from hydraulic fracturing tests by geomechanics modeling and soft computing. Journal of Petroleum Science and Engineering, 124:484-492. http://dx.doi.org/10.1016/j.petrol.2014.09.002

Zhang, Z.M., 2011. Achievements and problems of geotechnical engineering investigation in China. Journal of Zhejiang University-SCIENCE A (Applied Physics \& Engineering), 12(2):87-102. http://dx.doi.org/10.1631/jzus.A1000433

Zhao, D., Chen, Z., Cai, X., et al., 2007. Analysis of distribution rule of geostress in China. Chinese Journal of Rock Mechanics and Engineering, 26(6):1265-1271 (in Chinese).

Zhao, H., Ma, F., Xu, J., et al., 2012. In situ stress field inversion and its application in mining-induced rock mass movement. International Journal of Rock Mechanics and Mining Sciences, 53:120-128. http://dx.doi.org/10.1016/j.ijrmms.2012.05.005 


\section{中文概要}

\section{题 目：大型地下洞室群区域三维地应力场二次反演 分析}

目 的：地下洞室群区域地应力分布繁杂多变, 勘测点 因数量有限难以反映初始地应力场空间分布特 征。考虑工程区域内的地质构造、地形地貌及 河谷的发育演化史等因素，提出综合反映工程 区复杂地质条件及地层剥蚀过程的地应力场二 次反演方法, 揭示工程所在区域的三维地应力 场分布特征, 为地下工程的开挖加固设计提供 更加准确的基础资料。

创新点: 1. 基于地应力场反演基本理论, 建立逐步回归差异进化-支持向量机模型（SR-DE-SVM）的二 次反演非线性模型; 2. 通过 SR-DE-SVM 算法计 算流程, 成功模拟工程区域地应力场分布。

方 法: 1. 通过工程勘测分析, 推导出构造运动对工程
区域地应力场分布产生的影响（表 5 和图 13）；2. 基于智能反演方法，构建 SR-DE-SVM 的二次反演非线性模型（公式（10）），得到 SR-DE-SVM 算法的计算流程（图 2）；3. 通过 数值仿真模拟, 结合地质历史的发展过程, 验 证所提出的二次反演方法的可行性和有效性 （图 10 和 11）。

结 论: 1. 工程区域内初始地应力水平属中等, 主要受 到岩体自重与构造运动的双重影响。2. SR-DESVM 二次反演方法可更加清楚地明确初始地应 力形成的主导成因, 且更加准确、高效和真实 地模拟工程区域三维地应力场的分布规律; 3. 围岩类别对黄登地下洞室群区域内的初始地 应力场影响不大，仅在断层带及 III、IV 类凝灰 岩夹层带切割部位有显著的应力释放效应。

关键词: 初始地应力; 逐步回归; 支持向量机; 差异进 化; 有限元; 黄登地下洞室 